\title{
$N$-苯氧基乙酰胺导向的碳氢键官能团化反应研究进展
}

\author{
姜晓蕾郝佳奇周国庆侯程程胡芳东* \\ (临沂大学化学化工学院 临沂 276000)
}

\begin{abstract}
摘要 碳氢键活化反应因具有原子经济性和步骤简捷性的特点, 近年来成为有机化学研究的热点领域之一. 在传统的 碳氢键活化反应中, 通常需要加入等物质的量的氧化剂来实现催化剂的再生, 使催化循环顺利地发生. 而 $N$-苯氧基乙 酰胺作为一种新型的含有氧化型导向基的反应底物, 可以有效地避免等物质的量外加氧化剂的使用, 使碳氢键活化在 氧化还原中性的条件下进行. 综述了 $N$-苯氧基乙酰胺在有机合成领域特别是碳氢键活化反应中的最新研究进展, 并对 反应的机理进行了讨论.
\end{abstract}

关键词 $N$-苯氧基乙酰胺; 内氧化剂; $\mathrm{C}-\mathrm{H}$ 键活化; 偶联组分

\section{Recent Advances in N-Phenoxyacetamides Directed C-H Bond Functionalizations}

\author{
Jiang, Xiaolei Hao, Jiaqi Zhou, Guoqing Hou, Chengcheng Hu, Fangdong* \\ (School of Chemistry and Chemical Engineering, Linyi University, Linyi 276000)
}

\begin{abstract}
The $\mathrm{C}-\mathrm{H}$ bond activation has become one of the hot fields of organic chemistry in recent years due to its atom economy and step simplicity. In the conventional $\mathrm{C}-\mathrm{H}$ bond activations, an equivalent amount of oxidants is usually added to regenerate the catalyst and allow the catalytic cycle proceed smoothly. $\mathrm{N}$-Phenoxyacetamide, as a novel reaction substrate containing an oxidizing directing group, can effectively avoid the use of an equivalent external oxidants. Thus, the $\mathrm{C}-\mathrm{H}$ activation could be conducted under redox neutral conditions. In this paper, the latest research progress of $N$-phenoxyacetamides in the field of organic synthesis, especially $\mathrm{C}-\mathrm{H}$ bond activations is reviewed, and the mechanism of the reaction is discussed.

Keywords $N$-phenoxyacetamides; internal oxidant; $\mathrm{C}-\mathrm{H}$ bond activation; coupling partners
\end{abstract}

碳氢键广泛存在于各类有机分子中, 实现碳氢键的 高效转化是近年来化学家研究的热点领域之一. 由于碳 氢键较为惰性, 过渡金属催化的碳氢键活化是实现碳氢 键高效转化的重要措施. 在这一类反应中, 为了实现精 准的碳氢键活化, 导向基(或定位基)的引入往往是必不 可少的. 在导向基的作用下, 过渡金属可以选择性地实 现某一位置的碳氢键切断, 形成含有碳金属键的环状中 间体，与诸多类型的有机分子如烯烃、炔烃和亚胺等发 生反应构建结构多样性的目标分子 ${ }^{[1]}$, 使得过渡金属催 化的碳氢键活化反应在药物分子的合成以及有机发光 材料的开发等方面具有一定的用途.

在各类导向基中, 酰胺由于氮原子具有一定的配位 能力, 是一类常用的导向基团. 在酰胺导向的碳氢键活
化反应中，酰胺基团往往会保留在产物中，这在一定程 度上限制了产物分子的结构多样性. 另一方面，在这类 过渡金属催化的碳氢键活化反应中, 为了实现催化剂的 再生, 大多需要外加氧化剂, 这在一定程度上会增加副 反应和氧化剂的浪费. 在此基础上, 一种新型的含氧化 型导向基的反应底物应运而生, $N$-苯氧基酰胺是其中重 要的一类 ${ }^{[2]}$. 在 $N$-苯氧基乙酰胺中, $\mathrm{N}-\mathrm{O}$ 键的键能大约 是 $57 \mathrm{kcal} \cdot \mathrm{mol}^{-1}$, 比 $\mathrm{C}-\mathrm{C} 、 \mathrm{C}-\mathrm{O}$ 和 $\mathrm{C}-\mathrm{N}$ (键能在 $69 \sim$ $91 \mathrm{kcal} \cdot \mathrm{mol}^{-1}$ 之间)的键能小 ${ }^{[2 \mathrm{a}]}$, 因此它是一类较弱的 化学键. 在过渡金属催化的碳氢键活化反应中, 它可以 氧化低价态的过渡金属催化剂, 使其顺利完成催化循 环，避免了等物质的量的氧化剂的使用. 此外，这类导 向基可以选择性地离开目标分子或者转移到目标产物

\footnotetext{
* Corresponding author. E-mail: hufangdong@lyu.edu.cn

Received February 19, 2019; revised March 14, 2019; published online April 11, 2019.

Project supported by the National Natural Science Foundation of China (No. 21801109), the Natural Science Foundation of Shandong Province (No. ZR2018BB019), and the Higher Educational Science and Technology Program of Shandong Province (No. J17KA099).

国家自然科学基金(No. 21801109)、山东省自然科学基金(No. ZR2018BB019)、山东省高等学校科技计划(No. J17KA099)资助项目.
} 
中的其它位置, 从而可以通过催化体系的选择合成目标 产物. 近几年, $N$-苯氧基酰胺在有机合成领域特别是过 渡金属催化的碳氢键活化反应中得到了广泛的研究. 因 此, 本文根据偶联组分的不同分类综述了它的最新研究 进展.

\section{1 炔烃作为偶联组分}

炔烃具有较高的反应活性和较好的稳定性, 因此它 被广泛地应用于碳氢键活化反应中, 合成各类官能团化 的目标分子. 2013 年, 刘桂霞和陆熙炎课题组 ${ }^{[3]}$ 首次使 用 $N$-苯氧基乙酰胺作为反应底物, 发展了铑催化的 $N$ 苯氧基乙酰胺与炔烃的碳氢键活化反应, 选择性地合成 了烯胺和苯并呋喃产物(Scheme 1). 在反应过程中, $N$ 苯氧基乙酰胺中的 NOAc 部分既充当了导向基又作为 内氧化剂, 避免了外加氧化剂的使用, 因此, 这类反应 被定义为氧化还原中性的碳氢键活化反应。在 $\left[\left(\mathrm{Cp}^{*} \mathrm{RhCl}_{2}\right)_{2}\right] / \mathrm{CsOAc}$ 的催化体系下, 以甲醇作为溶剂,
$N$-苯氧基乙酰胺与炔烃反应得到烯胺; 而以二氯甲烷和 醋酸代替甲醇时，选择性地得到 2,3-二取代苯并呋喃化 合物. 无论是在酸性还是在标准反应条件下，苯并呋喃 产物均不能由烯胺得到, 同时, 作者探索了一系列溶剂 对产物比例的影响. 基于以上实验结果, 作者提出了 $R h^{\mathrm{III}} / \mathrm{Rh}^{\mathrm{I}} / \mathrm{Rh}^{\mathrm{III}}$ 的催化循环, 认为具有弱配位能力的溶剂 可以稳定七元环铑中间体，有利于还原消除过程的发 生，因此，经过还原消除、氧化加成和质子化过程得到 烯胺产物; 而在无配位能力或大位阻溶剂条件下，七元 环铑中间体中的铑氮键更容易质子化，经分子内取代反 应后得到苯并呋喃产物. 这一开创性的研究为后续 $N$ 苯氧基乙酰胺在碳氢键活化反应中的应用奠定了基础.

2016 年, 吴云东和 Houk 等 ${ }^{[4]}$ 采用理论计算的方法 对这一反应的机理进行了重新研究, 他们认为氧化加成 过程发生在还原消除过程之前, 提出了 $\mathrm{Rh}^{\mathrm{III}} / \mathrm{Rh}^{\mathrm{V}} / \mathrm{Rh}^{\mathrm{III}}$ 的 催化循环，并且认为反应过程中涉及 $R h(V)$ 氮宾中间体 (Scheme 2). 这一研究将为后续铑催化的氧化还原
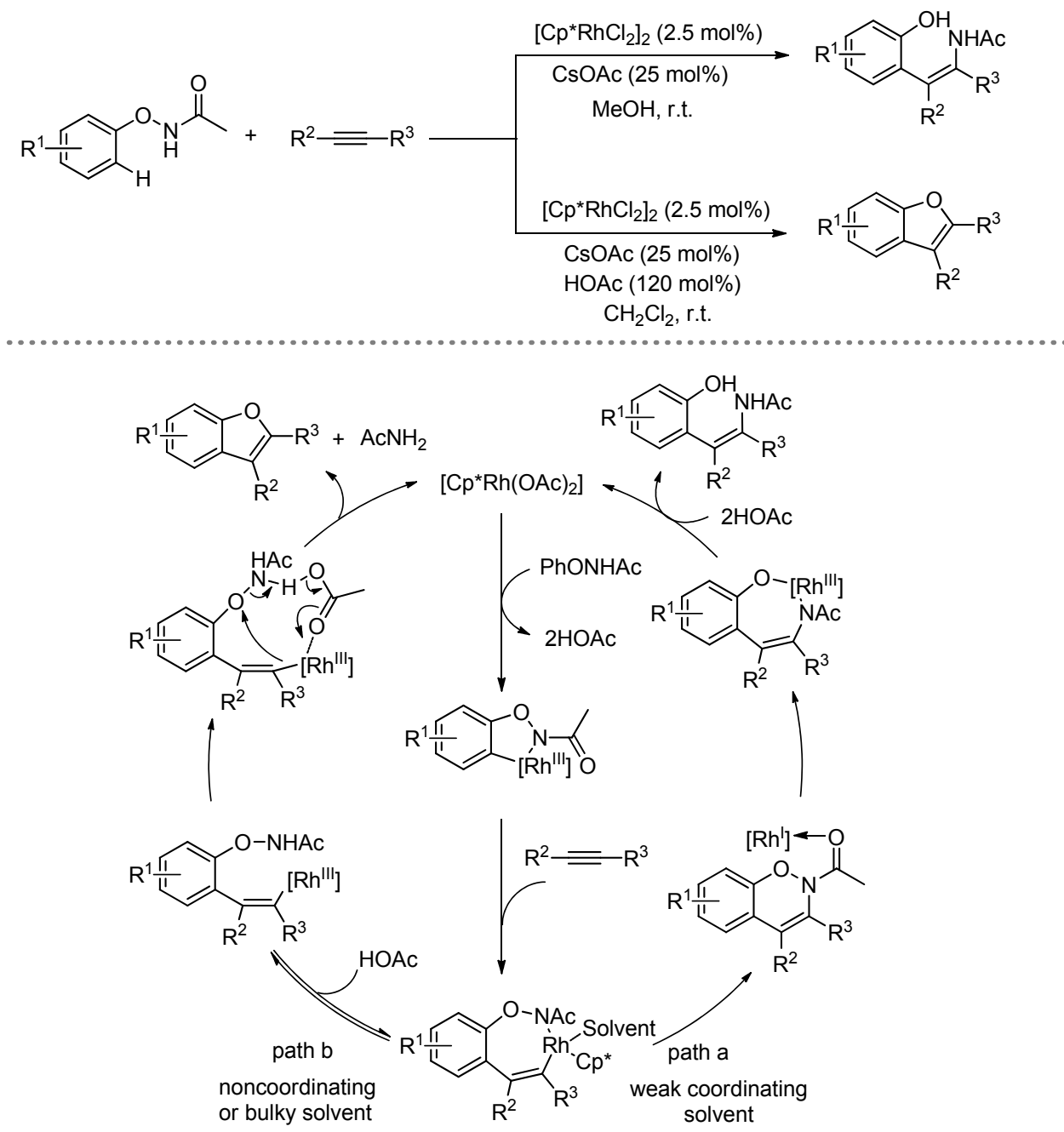

图式 1 铑催化的 $N$-苯氧基乙酰胺与炔烃的碳氢键活化反应

Scheme 1 Rhodium-catalyzed $\mathrm{C}-\mathrm{H}$ bond activation of $N$-phenoxyacetamides with alkynes 


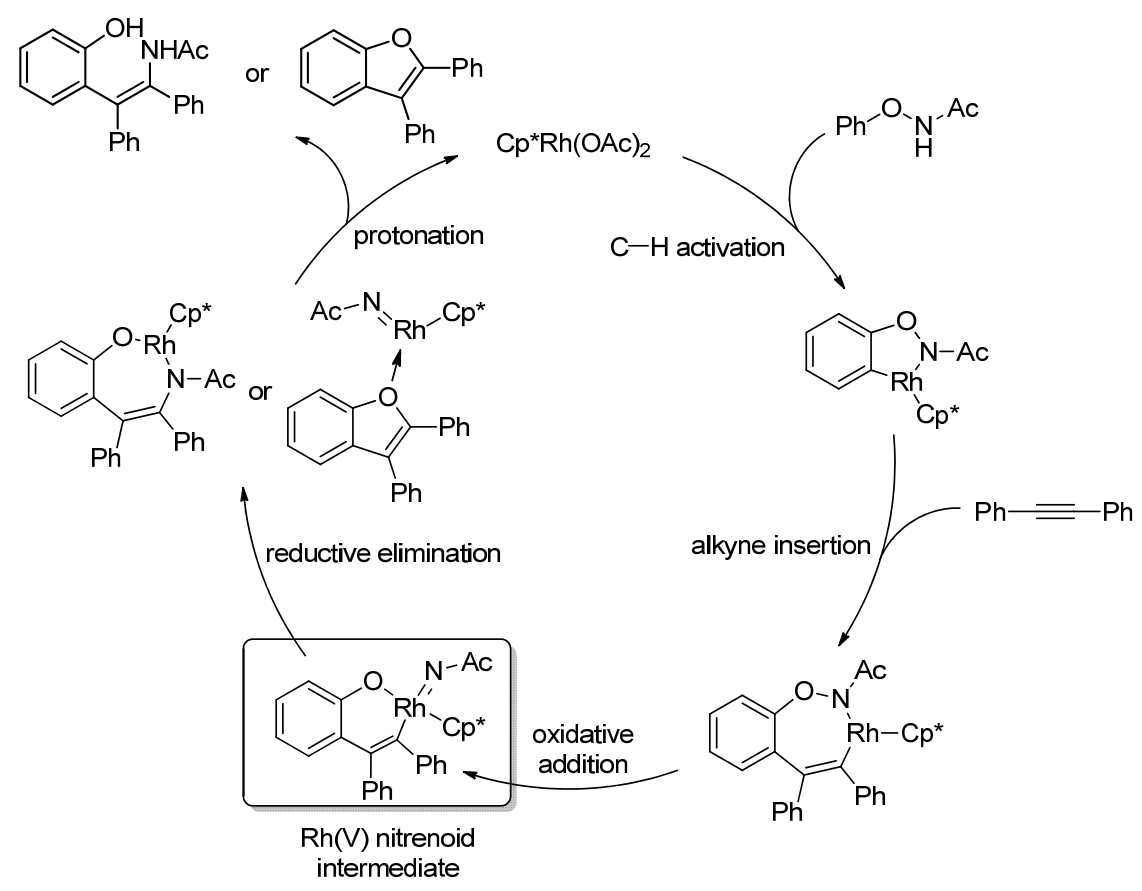

图式 2 铑催化的 $N$-苯氧基乙酰胺与炔烃的碳氢键活化反应机理

Scheme 2 The reaction mechanism of rhodium-catalyzed $\mathrm{C}-\mathrm{H}$ bond activation of $N$-phenoxyacetamides with alkynes

中性的碳氢键活化反应提供理论支持.

受到以上工作的启发, 赵劲课题组 ${ }^{[5]}$ 同样使用 $\left[\left(\mathrm{Cp}^{*} \mathrm{RhCl}_{2}\right)_{2}\right]$ 作为催化剂, 通过向反应体系中加入 $\mathrm{Ag}_{2} \mathrm{CO}_{3} 、 \mathrm{AgTFA}$ 或 $\mathrm{AgOAc}$ 等银盐, 实现了 $N$-苯氧基乙 酰胺与炔烃的串联环化反应, 以中等到较好的产率得到 了一系列并环类化合物(Scheme 3). 与刘桂霞和陆熙炎 课题组 ${ }^{[3]}$ 报道的反应相比, $\mathrm{Ag}_{2} \mathrm{CO}_{3}$ 使生成的烯胺中间体 继续发生脱氢环化反应, 构建了一类新型的苯并二氢呋
喃并噁唑类化合物; AgTFA 的加入使 $N$-苯氧基乙酰胺与 过量的炔烃反应合成了一系列多取代的异喹啉类化合 物; 而 $\mathrm{Ag}_{2} \mathrm{CO}_{3}$ 和 $\mathrm{AgTFA}$ 的同时加入实现了 $N$-苯氧基乙 酰胺与两种不同炔烃的碳氢键活化反应, 合成了结构更 加复杂的多取代异喹啉衍生物. 由于多取代异喹啉中含 有三芳基甲烷结构, 在 $\mathrm{AgOAc}$ 条件下被氧化为更复杂 的异喹啉衍生物. 这一反应同时构建了多根化学键, 显 著提高了合成效率，增加了产物分子结构多样性.<smiles>[R]C#C[R]</smiles>

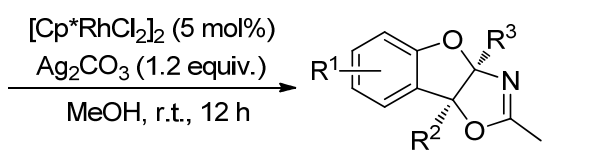<smiles>[R]C#Cc1ccccc1</smiles>

$\left[\mathrm{Cp}^{*} \mathrm{RhCl}_{2}\right]_{2}(5 \mathrm{~mol} \%)$ AgTFA (2.2 equiv.) CsOAc (2 eqiuv.) $\mathrm{MeOH}, 120^{\circ} \mathrm{C}, 10 \mathrm{~h}$<smiles>[R]c1c(-c2ccccc2)nc(C([R])c2ccccc2O)c2ccccc12</smiles><smiles>[R]C#C[R]</smiles>

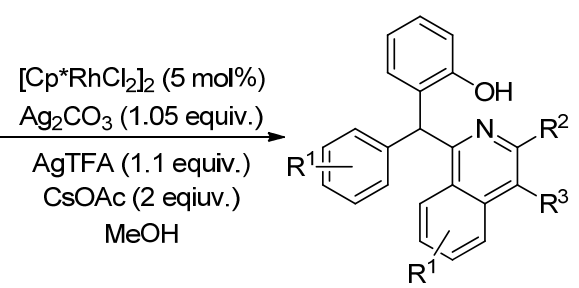

图式 3 铑催化的 $N$-苯氧基乙酰胺与炔烃的串联环化反应

Scheme 3 Rhodium-catalyzed cascade cyclization of $N$-phenoxyacetamides with alkynes 
与铑催化剂相比, 钉催化剂在 $N$-苯氧基酰胺参与 的碳氢键活化反应中应用较少. 2014 年, 刘桂霞和陆熙 炎课题组 ${ }^{[6]}$ 报道了钉催化的 $N$-苯氧基特戊酰胺与炔烃 的碳氢键活化反应，合成了一系列苯并呋喃衍生物，该 反应同样不需要外加氧化剂, 导向基中的 $\mathrm{N}-\mathrm{O}$ 键作为 内氧化剂, 使催化循环能够顺利的进行 (Scheme 4). 通 过控制实验，他们发现 $N$-苯氧基特戊酰胺在标准反应 条件下分解为苯酚和特戊酰胺, 而苯酚与炔烃反应并不 能生成目标产物, 这说明反应起始步骤不是 $\mathrm{N}-\mathrm{O}$ 键的 直接断裂. 同时, $N$-甲基取代的苯氧基特戊酰胺与炔烃 在标准反应条件下不能生成目标产物, 这说明 $\mathrm{N}-\mathrm{H}$ 键 是该反应能够顺利发生所必需的.
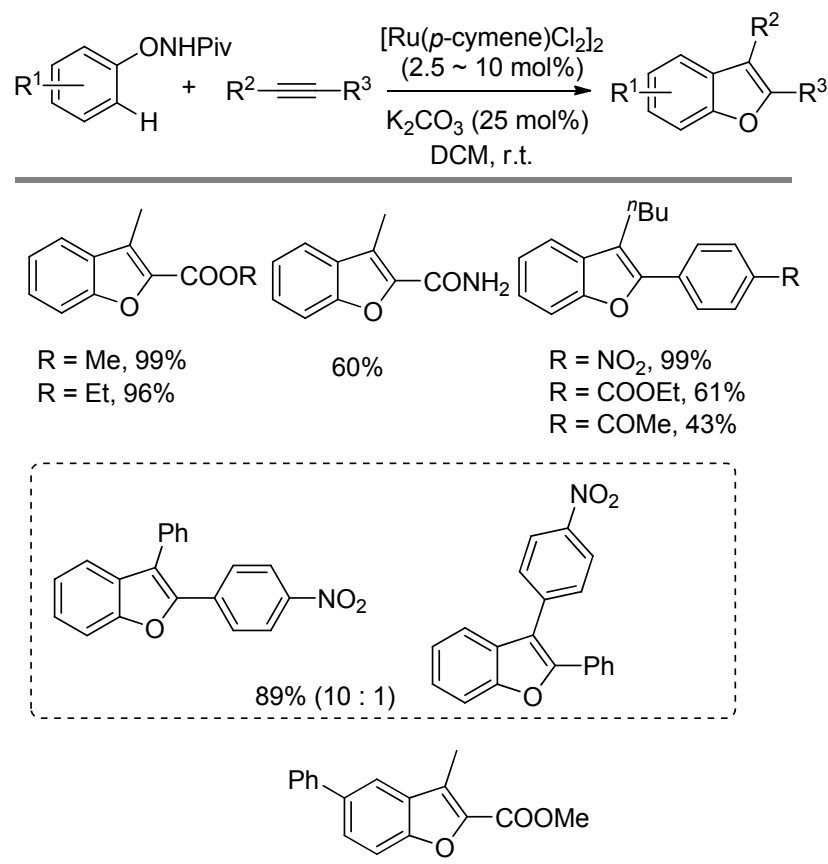

$88 \%$

图式 4 钉催化的 $N$-苯氧基特戊酰胺与炔烃的碳氢键活化反 应

Scheme 4 Ruthenium-catalyzed $\mathrm{C}-\mathrm{H}$ bond activation of $\mathrm{N}$-phenoxypivalamides with alkynes
同年，该课题组 ${ }^{[7]}$ 还报道了铑催化的 $N$-苯氧基乙酰 胺与炔丙基碳酸酯的碳氢键活化反应，在温和的条件下 高效地合成了苯丙二氢呋喃类化合物(Scheme 5). 该反 应具有较好的官能团容忍性和较高的产率。在反应过程 中, $N$-苯氧基乙酰胺与炔丙基碳酸酯首先经碳氢键活化 得到烯胺中间体，由于 $\mathrm{OBoc}$ 基团易于离去的特点，烯 胺中间体经分子内亲核取代反应得到目标产物. 该反应 可以进行克级制备, 并且产率几乎不受影响. 此外, 目 标产物在适当的反应条件下可以发生后续转化得到苯 并呋喃等产物。

2016 年, 谢应 ${ }^{[8]}$ 使用 $\left[\left(\mathrm{Cp}^{*} \mathrm{RhCl}_{2}\right)_{2}\right] / \mathrm{Cu}(\mathrm{OAc})_{2}$ 的催化 体系，实现了 $N$-苯氧基乙酰胺邻位酰基化，合成了 2-差 基二苯甲酮类化合物(Scheme 6). 可能的反应机理是 $N$ 苯氧基乙酰胺与炔烃在三价铑作用下发生碳氢键活化 反应得到烯胺中间体，该中间体被醋酸铜和氧气氧化得 到目标产物。作者通过控制实验合成了烯胺中间体，并 且该中间体在标准反应条件下以 $83 \%$ 的产率生成了目 标产物; 相反, 在氩气条件下, 该中间体不能转化得到 目标产物, 说明氧气是必不可少的.

2018 年, 易伟、周志和高辉等 ${ }^{[9]}$ 以炔丙醇作为偶联 组分, 发展了铑催化的 $N$-苯氧基乙酰胺与炔丙醇的碳 氢键活化反应，通过溶剂的控制高选择性地获得了查尔 酮和苯并呋喃类化合物(Scheme 7)。该反应条件温和, 官能团的兼容性好. 需要指出的是, 该方法可用于多巴 胺衍生物、酪氨酸衍生物和雌酮的官能团化. 机理实验 和理论计算表明, 炔丙醇中的羟基与导向基的氢键作用 以及与铑催化剂的配位作用对炔烃的区域选择性插入 起到了重要的作用. 作者合成了五元环铑中间体，该中 间体与炔丙醇在标准反应条件下能够顺利得到目标产 物，因此，他们认为反应的起始步骤是碳氢键活化形成 的五元环铑中间体，炔丙醇区域选择性插入铑碳键后形 成七元环铑中间体 (Scheme 8). 在大极性的溶剂中, 七 元环铑中间体发生分子内氧化加成形成五价铑氮宾

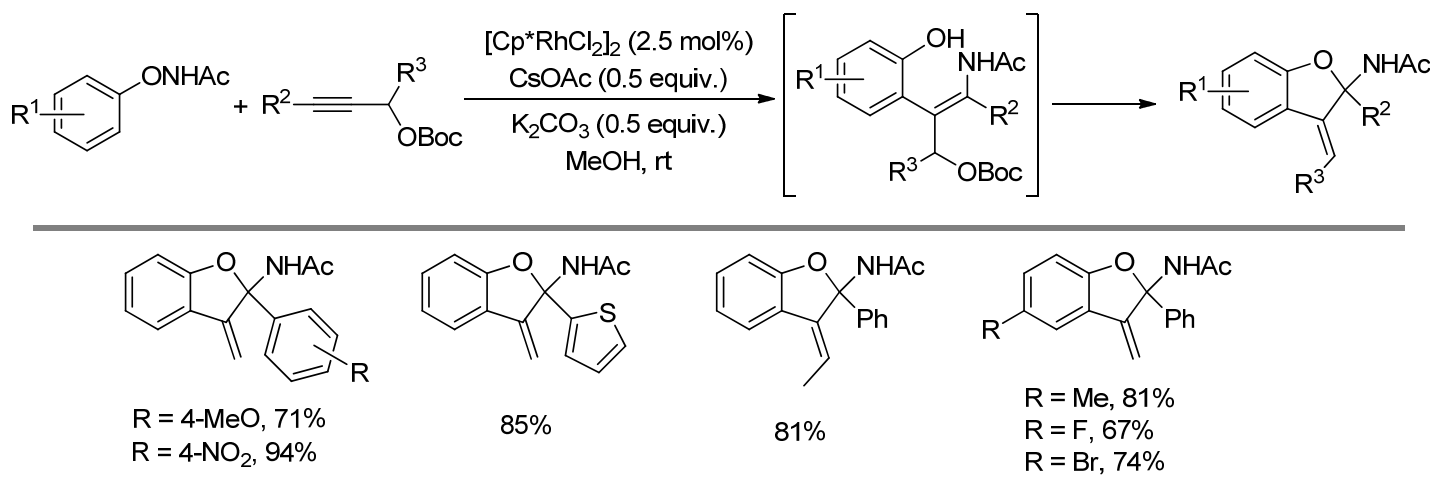

图式 5 铑催化的 $N$-苯氧基乙酰胺与炔丙基碳酸酯的碳氢键活化反应

Scheme 5 Rhodium-catalyzed $\mathrm{C}-\mathrm{H}$ bond activation of $\mathrm{N}$-phenoxyacetamides with propargyl carbonates 


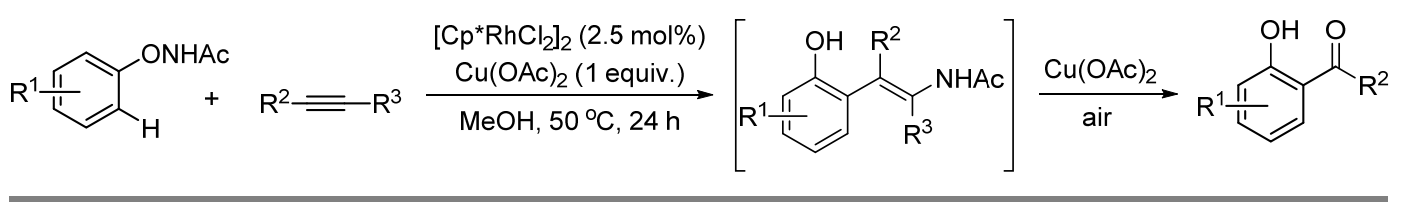<smiles>[R][M]1cccc(C(=O)c2ccccc2)c1O</smiles>

$\mathrm{R}=p-\mathrm{Me}, 88 \%$ $\mathrm{R}=p-\mathrm{Br}, 78 \%$

$\mathrm{R}=o-\mathrm{Me}, 44 \%$

$\mathrm{R}=m-\mathrm{Cl}, 65 \%$<smiles>O=C(c1ccsc1)c1ccccc1O</smiles>

$66 \%$<smiles>O=C(c1ccc(P)cc1)c1ccccc1O</smiles>

$\mathrm{R}=\mathrm{F}, 74 \%$ $\mathrm{R}=\mathrm{Cl}, 76 \%$<smiles>CC(=O)c1ccccc1O</smiles>

$68 \%$ (from but-2-yne) $60 \%$ (from prop-1-yn-1-ylbenzene)

图式 6 铑催化的 $N$-苯氧基乙酰胺碳氢键酰基化反应

Scheme 6 Rhodium-catalyzed $\mathrm{C}-\mathrm{H}$ bond acylation of $N$-phenoxyacetamides

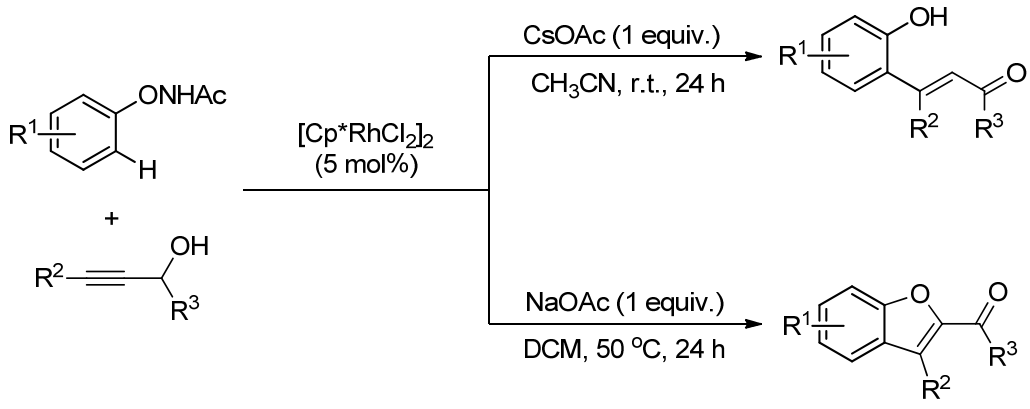<smiles>[R]c1ccc(O)c(/C(C)=C/C(=O)c2ccccc2)c1</smiles>

$\mathrm{R}={ }^{t} \mathrm{Bu}, 81 \%$

$\mathrm{R}=\mathrm{F}, 62 \%$

$\mathrm{R}=\mathrm{I}, 74 \%$

$\mathrm{R}=\mathrm{CN}, 45 \%$<smiles>[R]c1ccc2c(C)c(C(=O)c3ccccc3)oc2c1</smiles>

$\mathrm{R}=\mathrm{Me}, 78 \%$ $\mathrm{R}=\mathrm{Br}, 62 \%$<smiles>C/C(=C\C(=O)c1ccccc1)c1cc2ccccc2cc1O</smiles>

$61 \%$<smiles>CCCC(=CC(=O)c1ccccc1)c1ccccc1O</smiles>

$57 \%$<smiles>Cc1c(C(=O)c2ccccc2)oc2cc3c(cc12)C1CC[C@]2(C)C(=O)CC[C@H]2[C@H]1CC3</smiles>

$55 \%$<smiles>CCCC(=O)c1oc2ccccc2c1C1CC1</smiles>

$65 \%$<smiles>C/C(=C\C(=O)c1ccccc1)c1cc(CCNC(=O)OCc2ccccc2)ccc1O</smiles>

$55 \%$<smiles>CC(=O)NC(Cc1ccc(O)c(/C(C)=C/C(=O)c2ccccc2)c1)C(=O)O</smiles>

图式 7 铑催化的 $N$-苯氧基乙酰胺与炔丙醇的碳氢键活化反应

Scheme 7 Rhodium-catalyzed C-H bond activation of $N$-phenoxyacetamides with propargyl alcohols

中间体, 经 $\beta$-氢消除、氢转移和质子化过程得到查尔酮 产物; 在小极性的溶剂中, 七元环铑中间体首先发生 $\beta$ 氢消除得到一价铑中间体, 再经氢转移、氧化加成、碳 氧键还原消除和氧化等一系列过程得到苯并呋喃化合 物(Scheme 8). 在此基础上, 该课题组 ${ }^{[10]}$ 报道了铱催化 的 $N$-苯氧基乙酰胺与三级炔丙醇的碳氢键活化反应, 高效地合成了一系列苯并呋喃类化合物, 该反应具有中 等到较好的产率、良好的区域选择性和优秀的官能团容 忍性. 通过实验研究和理论计算证实炔丙醇中的羟基控 制反应的区域选择性和调控反应的活性.

几乎同时, 邓清海课题组 ${ }^{[11]}$ 报道了类似的反应, 他
们使用烷基取代的炔丙醇作为反应底物，实现了查尔酮 衍生物的高效合成(Scheme 9). 该反应具有区域和立体 选择性好、底物范围广和产率高等优点, 并且该方法可 以容易的进行克级制备. 作者也通过 X射线单晶衍射确 认了目标产物中双键的构型. 此外, 目标产物可以转化 得到三氮唑和苯并吡喃衍生物，展示了该反应良好的合 成应用价值.

2017 年, 李滨等 ${ }^{[12]}$ 报道了铑催化的 $N$-苯氧基乙酰 胺与 1-炔基磷硫化合物和氧化物的碳氢键活化反应，合 成了一系列苯并呋喃衍生物, 通过对磷硫化物和氧化物 的还原，定量地得到了含有苯并呋喃的三芳基磷化合物 


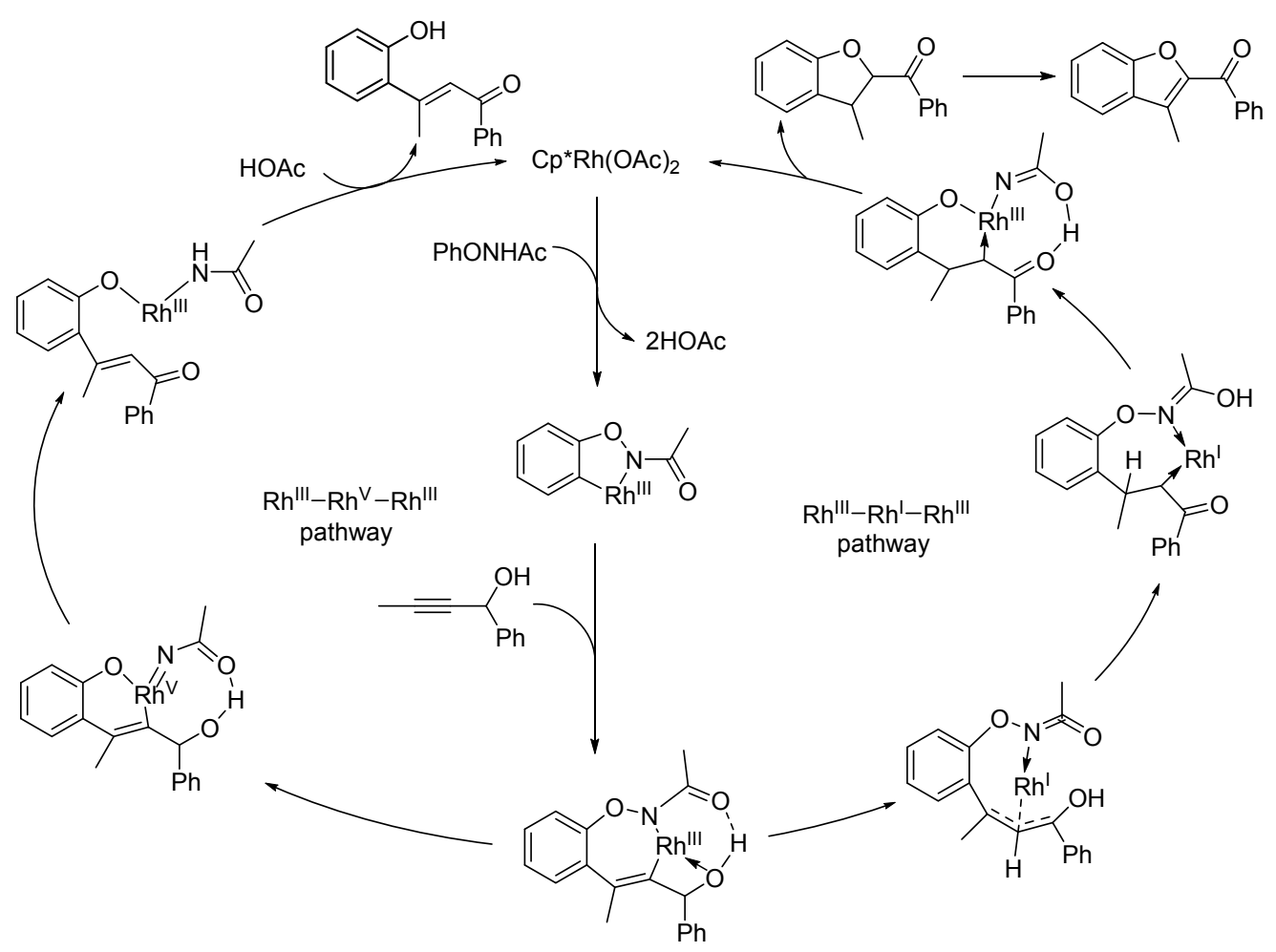

图式 8 可能的反应机理

Scheme 8 Possible reaction mechanism
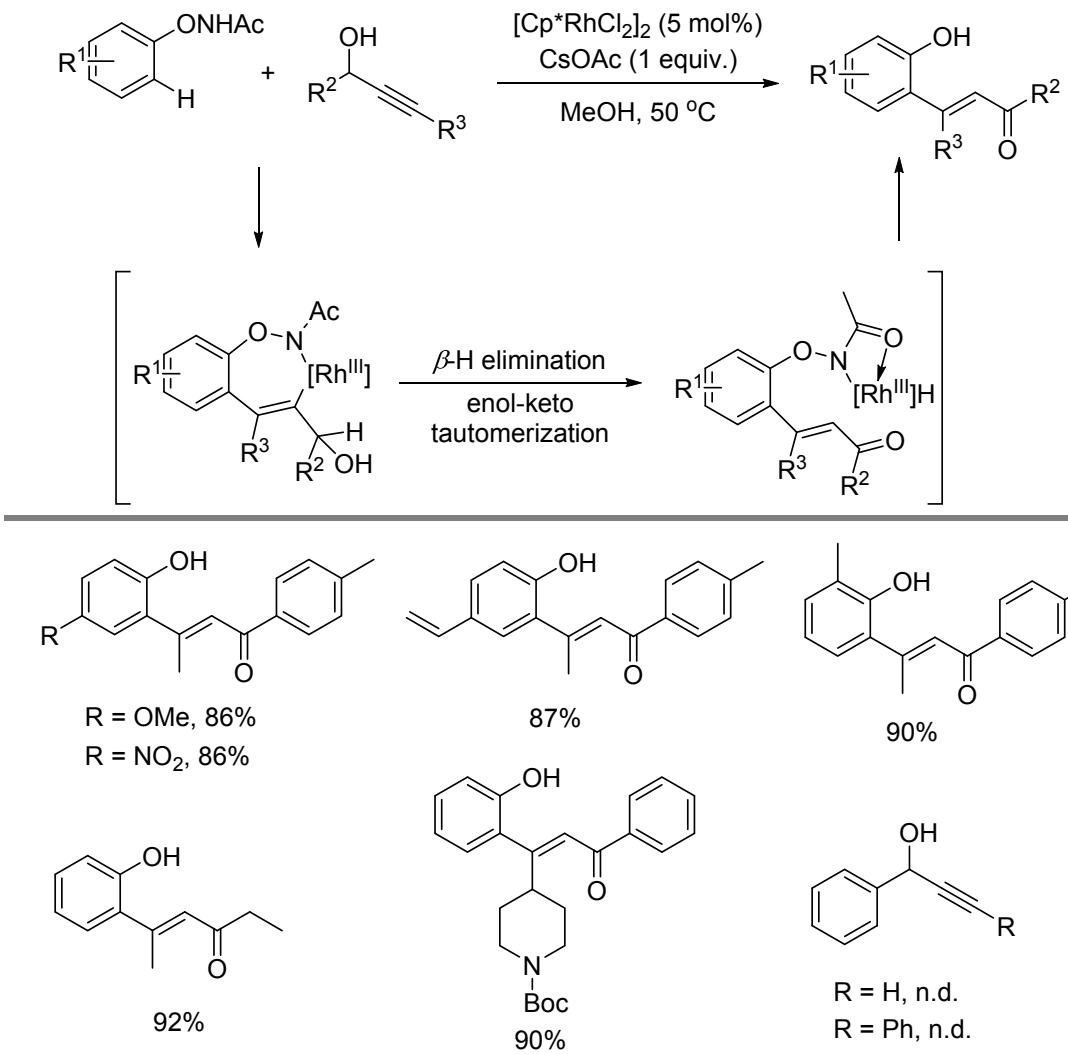

图式 9 铑催化查尔酮衍生物的合成

Scheme 9 Rhodium-catalyzed synthesis of chalcone derivatives 
(Scheme 10). 通过对苯并呋喃的三芳基磷化合物的耖 选，作者发现化合物 1 作为一类有效的配体，可以应用 于钯催化的 Suzuki-Miyaura 偶联反应和 BuchwaldHartwig 胺化反应中.

2018 年, 李洋和徐四龙等 ${ }^{[13]}$ 报道了铑催化的 $N$-苯 氧基乙酰胺与炔基环氧乙烷的碳氢键活化反应, 以中等 到较好的产率合成了多官能团化的苯并二氢呋喃类衍 生物(Scheme 11). 由于目标产物中含有烯丙醇和酰胺等 官能团, 可以发生后续转化得到多并环化合物, 同时, 它也可以在氮杂环卡宾条件下发生重排反应得到香豆 素衍生物. 该反应的机理与之前报道的反应 ${ }^{[3,4]}$ 类似, 唯 一不同的是, 得到的烯胺中间体可以发生分子内的 $\mathrm{S}_{\mathrm{N}} 2^{\prime}$ 反应, 从而得到了苯并二氢呋喃类衍生物. 紧接着, 该 课题组以炔基环丙烷作为起始原料, 研究了类似的反
应 $^{[14]}$. 通过碳氢键活化和环丙烷中碳碳键的断裂，同样 得到了苯并二氢呋喃类衍生物. 该反应具有广泛的底物 普适性和中等到较好的产率.在此类反应中，炔烃底物 中的环氧乙烷和环丙烷为烯胺中间体的环化反应提供 了平台.

三异丙基硅基乙炔也可作为一种合适的偶联组分 应用于碳氢键活化反应中. 2015 年，易伟和李兴伟等 ${ }^{[15]}$ 发展了铱催化的 $N$-苯氧基乙酰胺与三异丙基硅基乙炔 的交叉偶联反应，通过碳氢键活化，实现了导向基邻位 的炔基化(Scheme 12). 该反应在温和条件下进行，可以 兼容各种电性的取代基, 具有良好的底物普适性, 为邻 位炔基取代的苯酚类化合物的合成提供了一种有效的 方法. 目标产物在四丁基氟化胺条件下脱硅得到邻差基 苯乙炔，经后续转化可以得到苯并呋喃和查尔酮等产
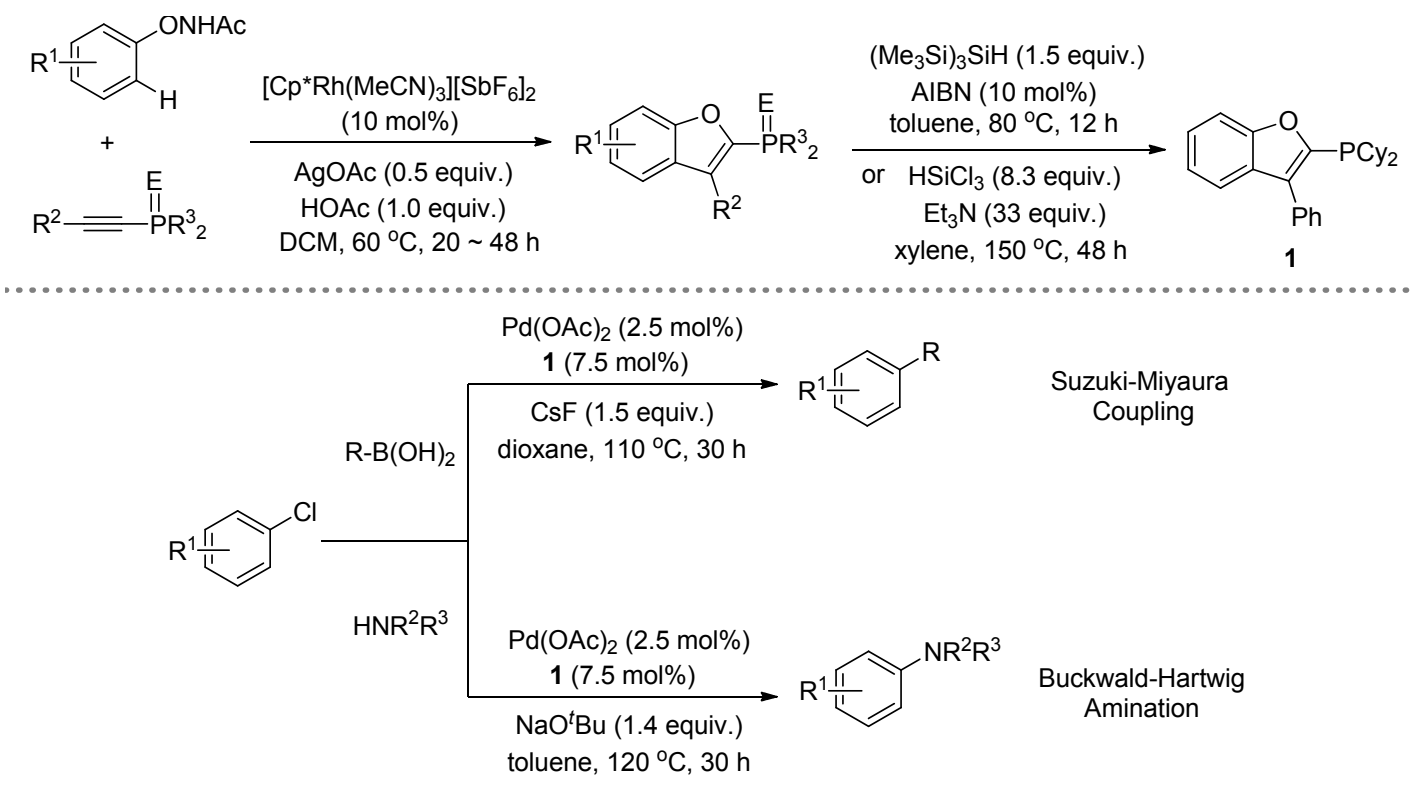

图式 10 铑催化的含膦苯并呋喃衍生物的合成及其在交叉偶联反应中的应用

Scheme 10 Rhodium-catalyzed synthesis of phosphine-containing benzofuran derivatives and their application in cross-coupling reactions

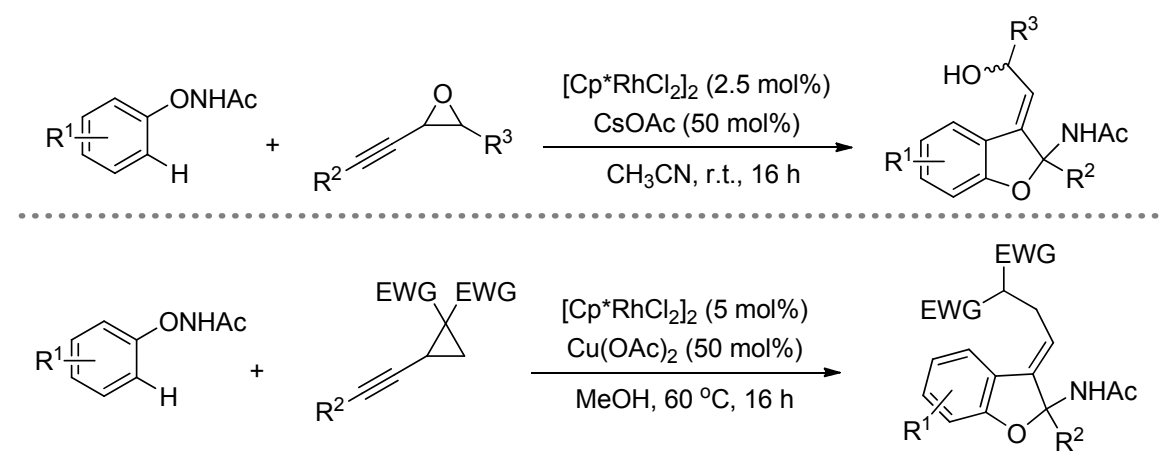

图式 11 铑催化的 $N$-苯氧基乙酰胺与炔基环氧乙烷或炔基环丙烷的碳氢键活化反应

Scheme 11 Rhodium-catalyzed $\mathrm{C}-\mathrm{H}$ bond activation of $N$-phenoxyacetamides with alkynyloxiranes or alkynylcyclopropanes 


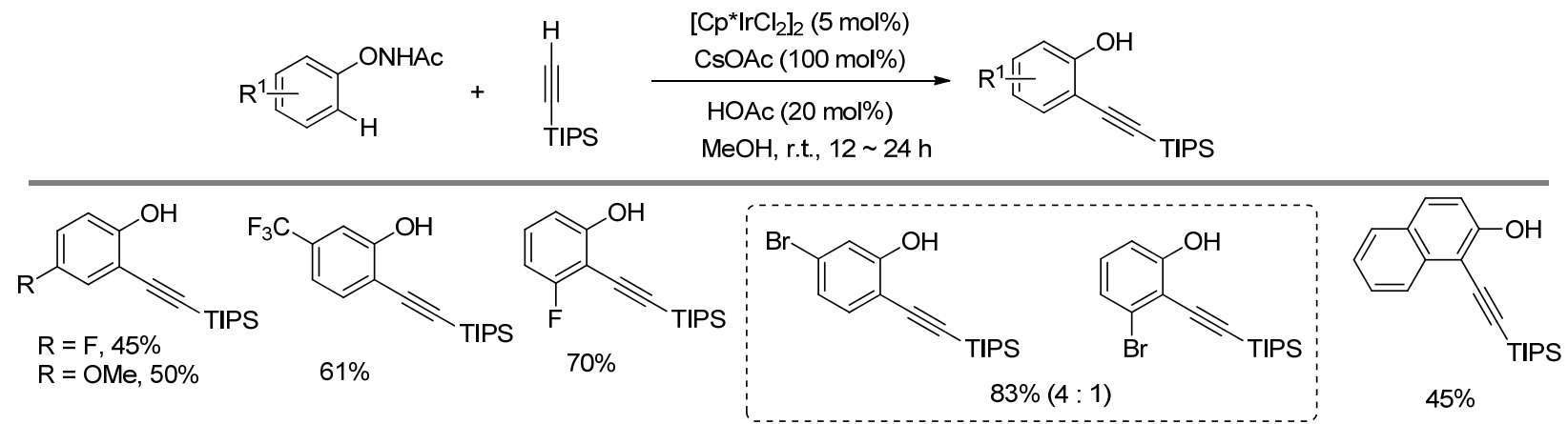

图式 12 铱催化的 $N$-苯氧基乙酰胺与三异丙基硅基乙炔的碳氢键活化反应

Scheme 12 Iridium-catalyzed $\mathrm{C}-\mathrm{H}$ bond activation of $\mathrm{N}$-phenoxyacetamides with TIPS-acetylenes

物. 作者通过 $N$-苯氧基乙酰胺与 $\left[\left(\mathrm{Cp}^{*} \mathrm{IrCl}_{2}\right)_{2}\right]$ 反应合成 了五元环铱中间体，该中间体与三异丙基硅基乙炔反 应, 以 $68 \%$ 的产率得到目标产物, 说明催化循环中可能 涉及碳氢键活化过程并且五元环铱可能是反应的关键 中间体.

\section{2 烯烃作为偶联组分}

与炔烃类似的是, 烯烃作为一类常见的有机化合物 在 $N$-苯氧基乙酰胺参与的碳氢键活化反应中也有广泛 的应用. 2013 年, 刘桂霞和陆熙炎课题组 ${ }^{[16]}$ 报道了铑催 化的 $N$-苯氧基乙酰胺与烯烃的碳氢键活化反应, 该反
应具有条件温和、官能团兼容性好和底物范围广等优点, 在反应过程中下, 导向基中的 $\mathrm{N}-\mathrm{O}$ 键作为内氧化剂, 使酰胺部分脱离目标产物, 获得了一系列邻位烯基取代 的苯酚类衍生物(Scheme 13). 在机理研究上, 他们使用 $N$-烷基取代的苯氧基乙酰胺作为反应底物，在标准反应 条件下与烯烃反应未能得到目标产物, 说明了导向基中 的 $\mathrm{N}-\mathrm{H}$ 键在该反应中发挥着重要的作用. 经过机理实 验探索，他们推测反应可能经过碳氢键活化、烯烃插入、 $\beta$-氢消除、还原消除、氧化加成和质子化等过程生成了 目标产物. 2016 年, 该课题组 ${ }^{[17]}$ 使用丙烯酰胺作为偶联 组分, 在类似的催化体系下, 实现了 $N$-苯氧基乙酰胺邻

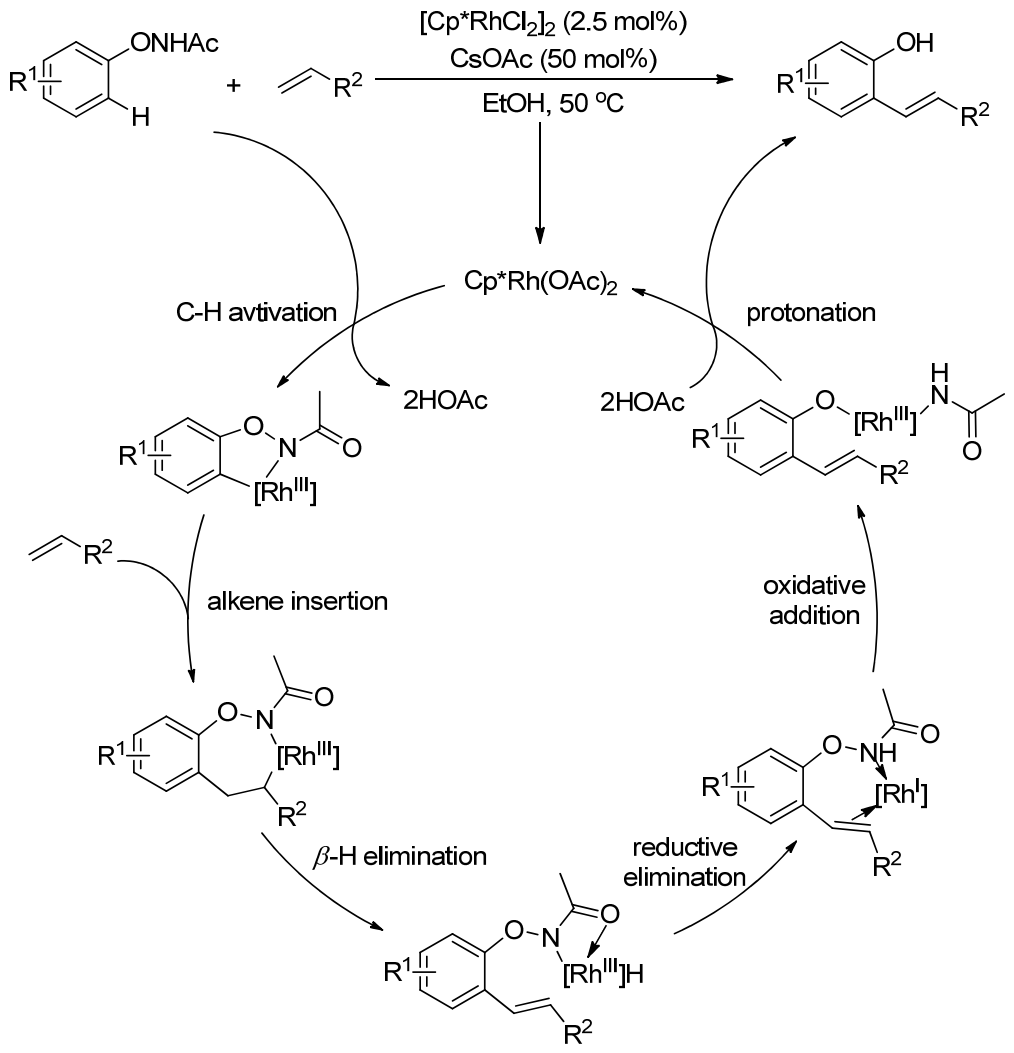

图式 13 铑催化的 $N$-苯氧基乙酰胺与烯烃的碳氢键活化反应

Scheme 13 Rhodium-catalyzed $\mathrm{C}-\mathrm{H}$ bond activation of $N$-phenoxyacetamides with alkenes 
位的烷基化, 导向基中的酰胺基团同时转移到了目标产 物中(Scheme 14). 通过机理实验研究, 他们认为丙烯酰 胺中的氮原子具有配位能力, 在七元环铑中间体中可以 与中心铑原子配位, 使得铑原子的配位数达到饱和, 从 而阻止了 $\beta$-氢消除过程, 经过还原消除、氧化加成和质 子化过程(即 $\mathrm{Rh}^{\mathrm{III}} / \mathrm{Rh}^{\mathrm{I}} / \mathrm{Rh}^{\mathrm{III}}$ 催化循环)或者质子化、氧化 加成、还原消除和质子化过程(即 $\mathrm{Rh}^{\mathrm{III}} / \mathrm{Rh}^{\mathrm{V}} / \mathrm{Rh}^{\mathrm{III}}$ 催化循 环)生成目标产物. 值得注意的是, 丙烯酰胺上取代基 的空间位阻对该反应具有重要影响，例如，当丙烯酰胺 上连有三苯氧基时, 仅能以 $15 \%$ 的产率得到目标产物, 主要的副产物是酰胺取代的苯并二氢呋喃.

利用相同的策略, 李洋和徐四龙等 ${ }^{[18]}$ 发展了铑催 化的 $N$-苯氧基乙酰胺与 1,1 -二取代烯烃的碳氢键活化 反应，合成得到了苯并二氢呋喃类化合物(Scheme 15). 在反应过程中, 烯烃中的酰胺基团通过与中心金属铑配 位使其配位数达到饱和, 避免了 $\mathrm{C}\left(\mathrm{sp}^{3}\right)-\mathrm{Rh}$ 的 $\beta$-氢消除 过程. 该反应条件温和, 具有良好到优秀的产率, 为 2 位酰胺和酯基同时取代的苯并二氢呋喃类衍生物的合
成提供了一种简便的方法. 虽然 1,1-二取代烯烃可应用 于该反应，但是，由于空间位阻的原因，三取代的烯烃 并不适用于该反应. 通过 $N$-苯氧基特戊酰胺与乙酰胺 取代的烯烃和 $N$-苯氧基乙酰胺与丙酰胺取代的烯烃的 底物交叉反应实验证实，目标产物中的酰胺基团来自于 烯烃. 对于该反应的机理, 作者提出了 $\mathrm{Rh}^{\mathrm{III}} / \mathrm{Rh}^{\mathrm{I}} / \mathrm{Rh}^{\mathrm{III}}$ 和 $\mathrm{Rh}^{\mathrm{III}} / \mathrm{Rh}^{\mathrm{V}} / \mathrm{Rh}^{\mathrm{III}}$ 两种可能的催化循环过程, 而 $R h^{\mathrm{III}} / R h^{\mathrm{I}} / R h^{\mathrm{III}}$ 的循环过程与底物交叉实验结果相悖, 因 此, 作者认为 $\mathrm{Rh}^{\mathrm{III}} / \mathrm{Rh}^{\mathrm{V}} / \mathrm{Rh}^{\mathrm{III}}$ 的催化循环是一种更可能的 反应途径.

Cheng 等 ${ }^{[19]}$ 于 2015 年报道了烯基锡试剂作为偶联 组分, 酰胺作为导向基的碳氢键活化反应, 通过碳氢键 活化、转金属、还原消除、氧化加成和质子化等过程, 获 得了一系列的 2-乙烯基苯甲酰胺和 2-乙烯基苯酚. 通过 机理实验研究发现, 醋酸盐对转金属过程具有重要的作 用. 无论是给电子还是吸电子的 $N$-苯氧基乙酰胺均能 顺利发生反应得到目标产物，体现了该反应良好的底物 普适性。

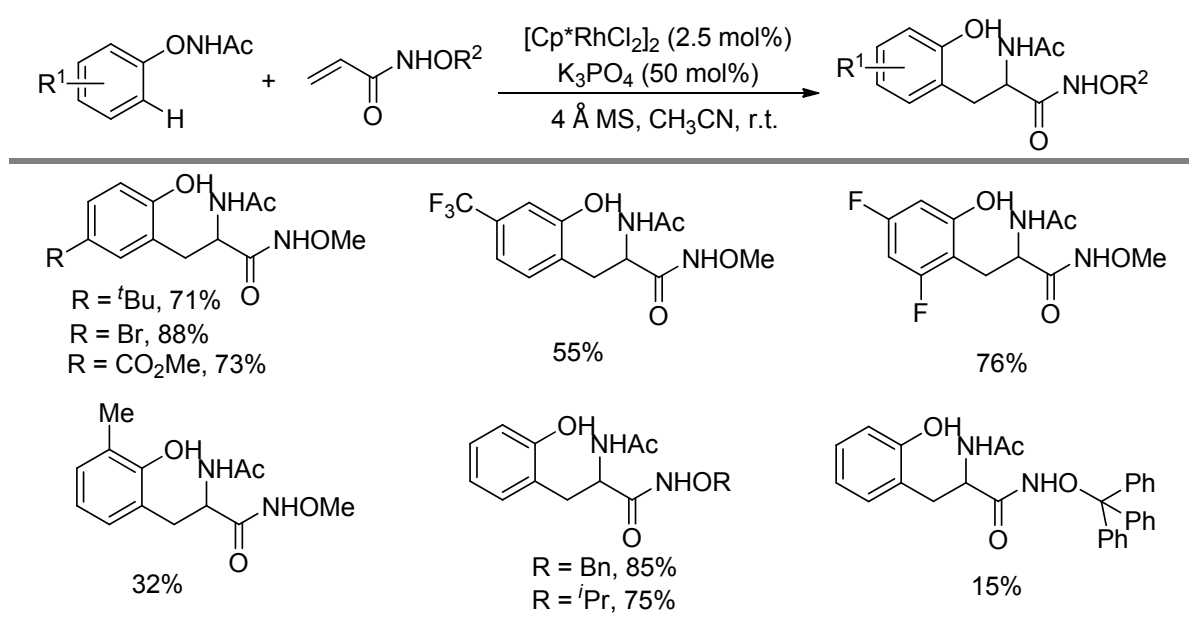

图式 14 铑催化的 $N$-苯氧基乙酰胺与丙烯酰胺的碳氢键活化反应

Scheme 14 Rhodium-catalyzed $\mathrm{C}-\mathrm{H}$ bond activation of $N$-phenoxyacetamides with acrylamides

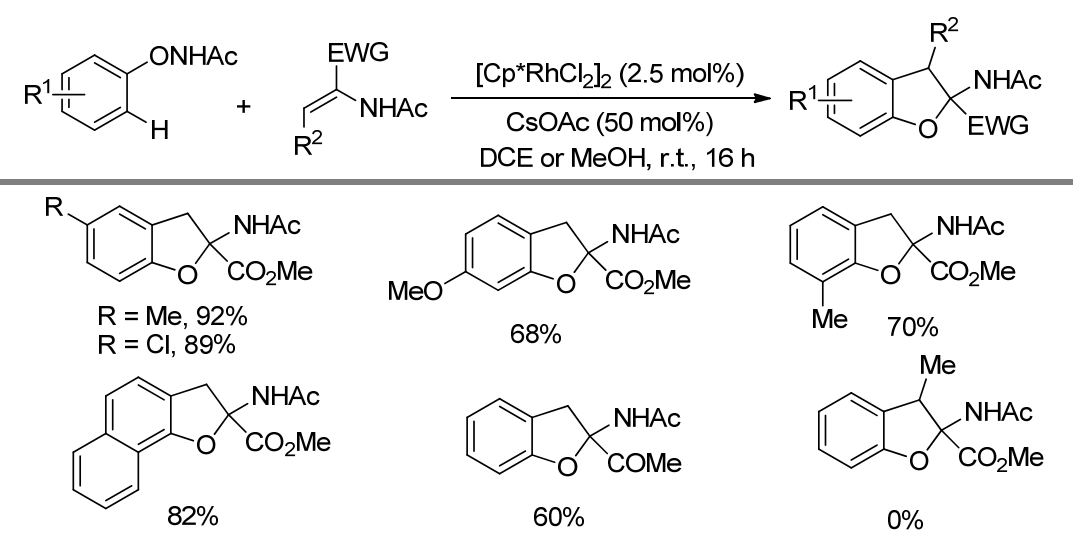

图式 15 铑催化的 $N$-苯氧基乙酰胺与 1,1-二取代烯烃的碳氢键活化反应

Scheme 15 Rhodium-catalyzed $\mathrm{C}-\mathrm{H}$ bond activation of $\mathrm{N}$-phenoxyacetamides with 1,1-disubstituted alkenes 
周兵和陈玉等 ${ }^{[20]}$ 使用 $\left[\left(\mathrm{Cp}^{*} \mathrm{RhCl}_{2}\right)_{2}\right] / \mathrm{Zn}(\mathrm{OAc})_{2}$ 的催 化体系, 实现了 $N$-苯氧基乙酰胺与烯丙醇的碳氢键烷 基化反应, 以良好到优秀的收率得到了一系列官能团化 的 $\beta$-芳基酮衍生物 (Scheme 16). 在催化体系中, $\mathrm{Zn}(\mathrm{OAc})_{2}$ 不仅可用于形成活泼的催化物种, 同时还能 用于活化烯丙醇. 目标产物 3-(2-羟基苯基)-1-苯基丙酮 经后续转化可以得到苯并二氢呋喃和色满衍生物.

2018 年, 易伟和余细勇等 ${ }^{[21]}$ 报道了铑催化的 $N$-苯 氧基乙酰胺与 $\alpha$-亚甲基- $\beta$-丁内酯的碳氢键活化/[3+3]
串联环化反应，合成了一系列苯并吡喃-3-羧酸类化合 物(Scheme 17). 该反应条件温和，具有良好的官能团耐 受性和底物普适性, 为苯并吡喃-3-羧酸衍生物的合成 提供了一种有效的方法. 反应所得产物可以与烯烃发生 后续碳氢键官能团反应或者在三氟甲磺酸条件下发生 自身的环化反应，得到两种多并环化合物，说明了该方 法具有良好的合成应用价值. 作者经过详细的机理实验 研究和理论计算认为 $\mathrm{Rh}^{\mathrm{III}} / \mathrm{Rh}^{\mathrm{V}} / \mathrm{Rh}^{\mathrm{III}}$ 的催化循环是一种 更有利的反应途径.
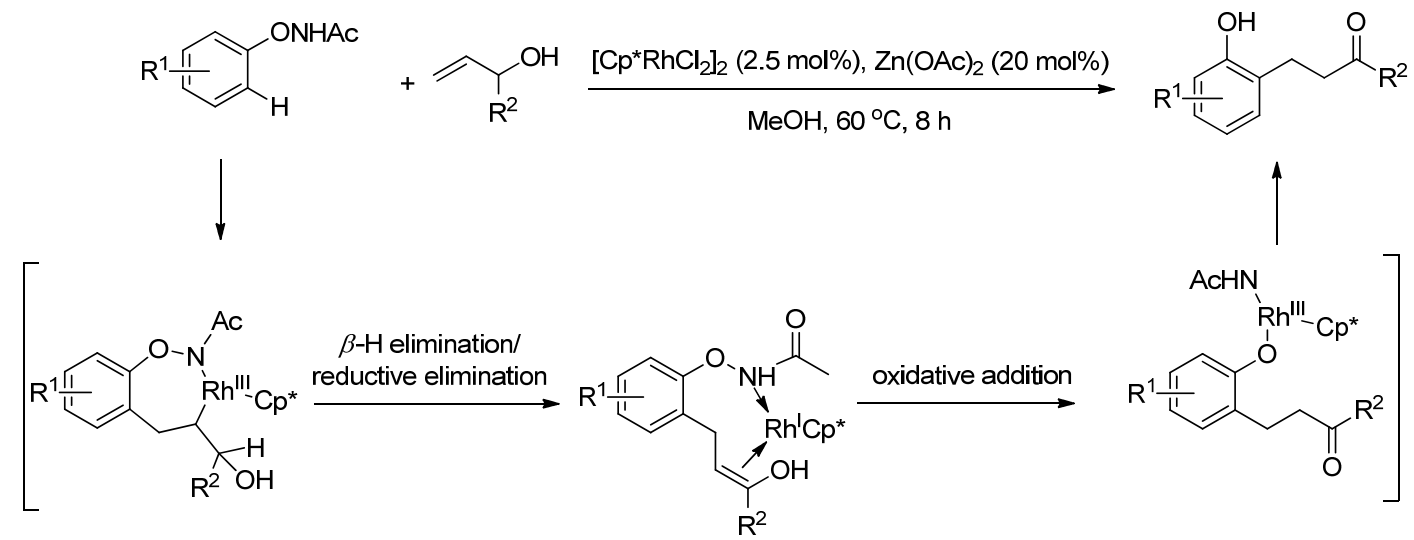

图式 16 铑催化的 $N$-苯氧基乙酰胺与烯丙醇的碳氢键活化反应

Scheme 16 Rhodium-catalyzed $\mathrm{C}-\mathrm{H}$ bond activation of $N$-phenoxyacetamides with allylic alcohols

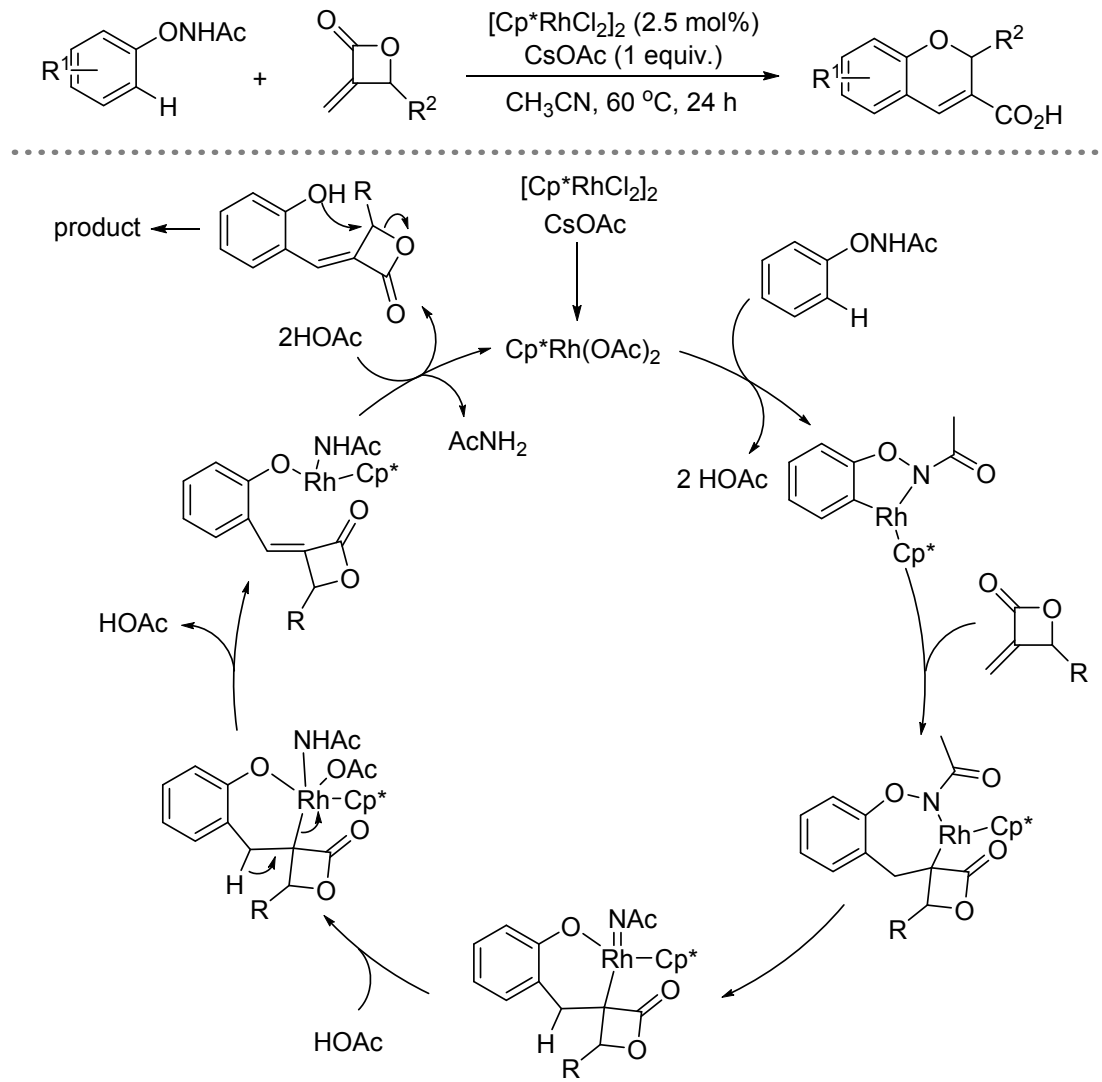

图式 17 铑催化的 $N$-苯氧基乙酰胺与 $\alpha$-亚甲基- $\beta$-丁内酯的碳氢键活化/[3+3]串联环化反应

Scheme 17 Rhodium-catalyzed $\mathrm{C}-\mathrm{H}$ activation/[3+3] annulation sequence of $N$-phenoxyacetamides with methyleneoxetanones 
2014 年, 王剑波课题组 ${ }^{[22]}$ 报道了铑催化的 $N$-苯氧 基乙酰胺与环丙烯的碳氢键活化反应, 以环丙烯作为三 碳单元, 实现了 $2 H$-苯并吡喃的合成(Scheme 18). 该反 应条件温和, 底物范围广. 对于该反应的机理, 作者认 为 $N$-苯氧基乙酰胺在三价铑催化剂作用下首先发生碳 氢键活化形成五元环铑中间体, 该中间体与环丙烯反应 后形成铑卡宾, 经转移插入、1,3-烯丙基迁移和分子内 取代反应生成目标产物并再生催化剂. 除此之外, 作者 认为环丙烯的插入和 $\beta$-碳消除也是一种可能的反应途 径. 随后, 夏远志 ${ }^{[23]}$ 和李娟 ${ }^{[24]}$ 两个课题组几乎同时对该 反应的机理进行了理论计算研究, 他们均认为反应可能 经过五价铑氮宾关键中间体. 2018 年, Glorius 课题组 ${ }^{[25]}$ 使用酯基取代的环丙烯作为反应底物, 在类似的催化体
系下，实现了 $N$-苯氧基乙酰胺邻位碳氢键官能团化，构 建了一系列 2-芳基呋喃类化合物(Scheme 19). 无论是给 电子还是吸电子取代基在该反应条件下都能兼容. 作者 对该反应涉及的四种可能反应途径进行了初步的探讨, 当在标准反应中加入 $\mathrm{D}_{2} \mathrm{O}$, 反应回收得到的环丙烯没有 发生氢氝交换, 因此, 他们认为反应可能经过碳氢键活 化、环丙烯的插入、铑氮宾的形成、还原消除、质子化 和环化异构化等过程.

2017 年, Glorius 课题组 ${ }^{[26]}$ 将碳氢键活化与外格奈 尔-麦尔外因(Wagner-Meerwein)重排结合，实现了铑催 化的 $N$-苯氧基乙酰胺与 7-氮杂苯并降冰片二烯的交叉 偶联反应，构建了一类新型的桥连多环分子(Scheme $20)$. 通过 $\left[\left(\mathrm{Cp}^{*} \mathrm{RhCl}_{2}\right)_{2}\right]$ 与 $N$-苯氧基乙酰胺反应，作者合

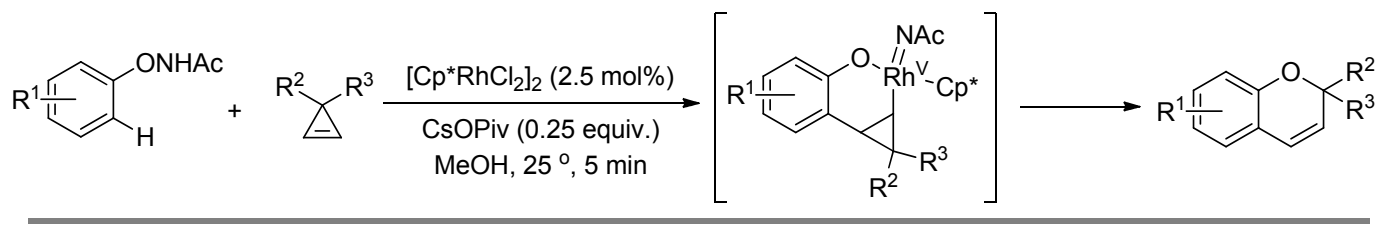<smiles>CC1(C)C=Cc2ccccc2O1</smiles>

$86 \%$<smiles>C=Cc1ccc2c(c1)C=CC(C)(CCCCCC)O2</smiles>

$88 \%$<smiles>CC1(Cc2ccccc2)C=Cc2ccccc2O1</smiles>

$70 \%$

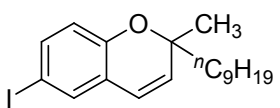

$74 \%$<smiles>C1=CC(c2ccccc2)(c2ccccc2)Oc2ccccc21</smiles>

$62 \%$<smiles>CCCCCCCCCCCC1(C)C=Cc2cccc(C)c2O1</smiles>

$84 \%$

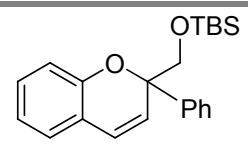

$60 \%$<smiles>CC1(C)C=Cc2c(Cl)cc(Cl)cc2O1</smiles>

图式 18 铑催化的 $N$-苯氧基乙酰胺与环丙烯的碳氢键活化反应

Scheme 18 Rhodium-catalyzed $\mathrm{C}-\mathrm{H}$ bond activation of $N$-phenoxyacetamides with cyclopropenes

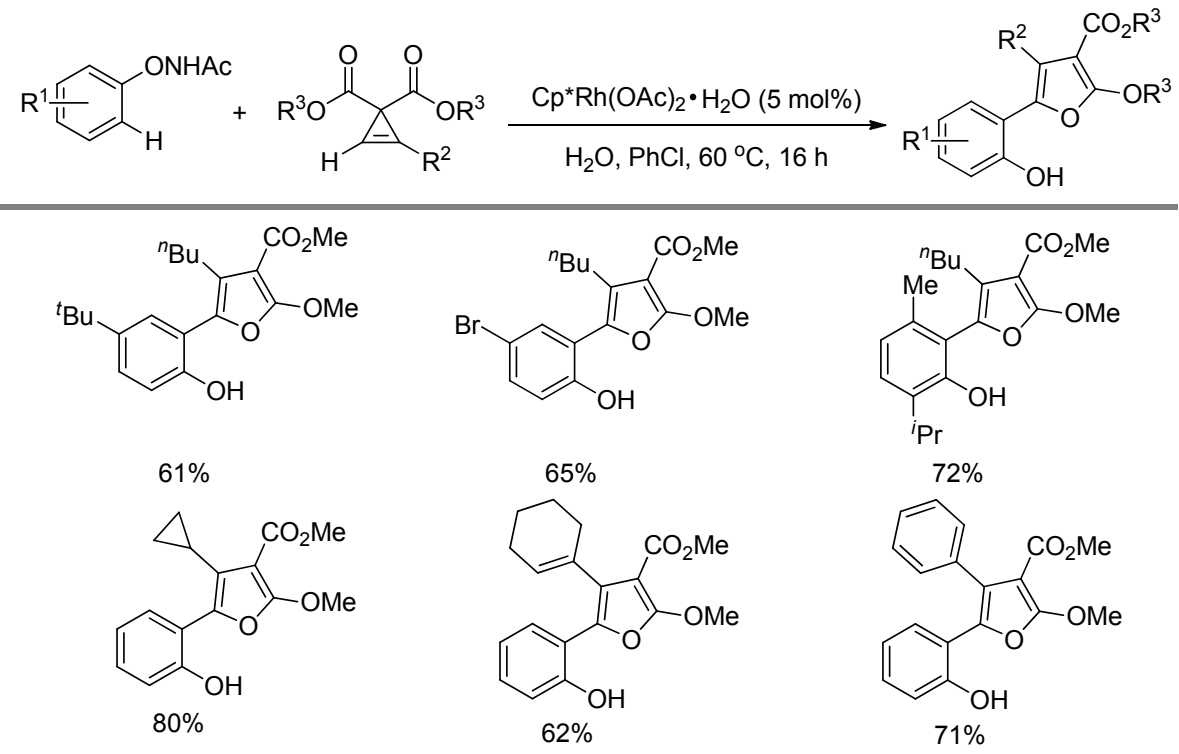

图式 19 铑催化的 $N$-苯氧基乙酰胺与酯基环丙烯的碳氢键活化反应

Scheme 19 Rhodium-catalyzed $\mathrm{C}-\mathrm{H}$ bond activation of $\mathrm{N}$-phenoxyacetamides with cyclopropenyl esters 

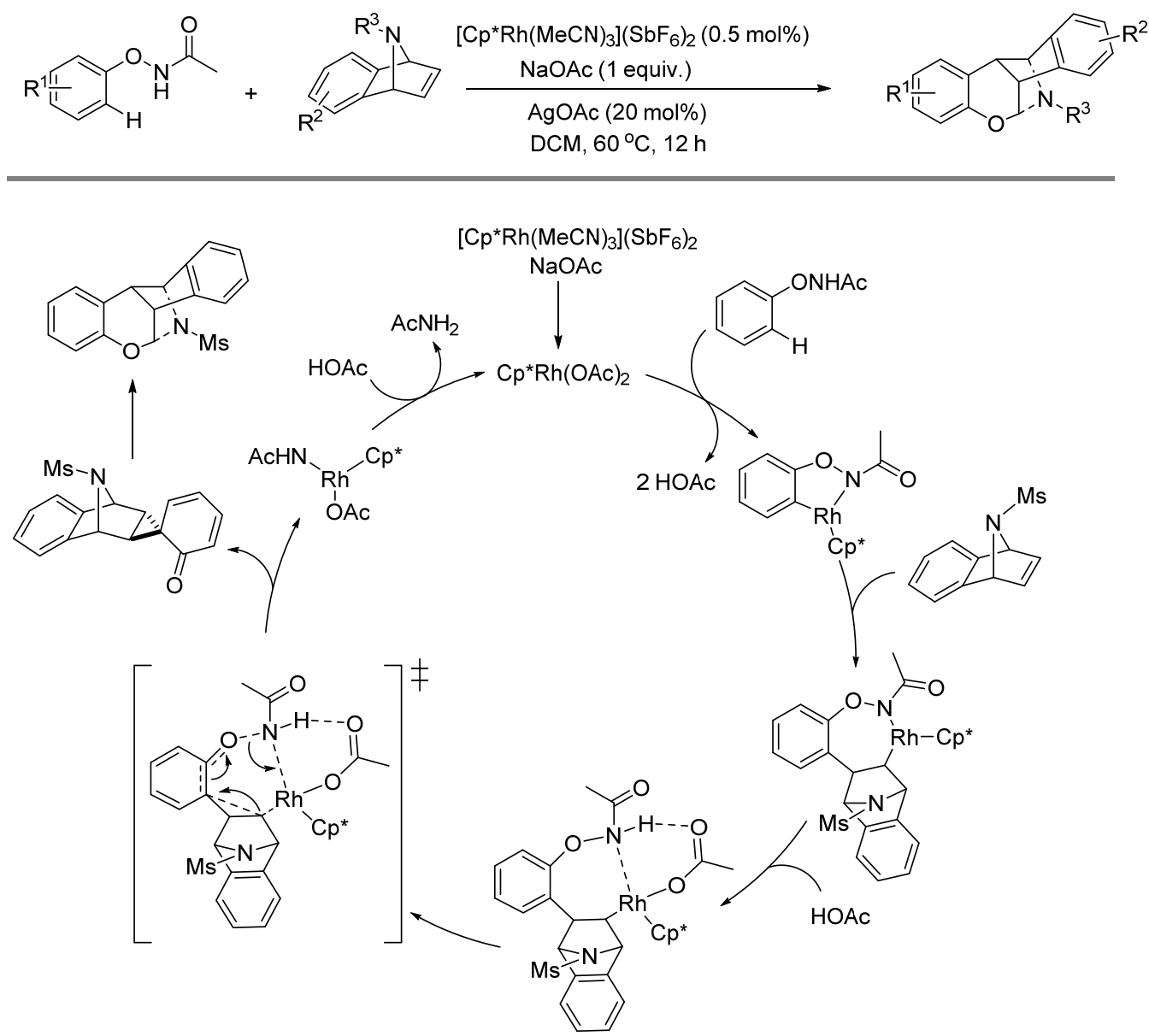

图式 20 铑催化的 $N$-苯氧基乙酰胺与 7-氮杂苯并降冰片二烯的交叉偶联反应

Scheme 20 Rhodium-catalyzed cross-coupling reactions of $N$-phenoxyacetamides with 7 -azabenzonorbornadienes

成了五元环铑中间体. 在 $2 \mathrm{~mol} \%$ 该中间体存在下, 反应 底物能够顺利的发生转化, 以 $83 \%$ 的产率得到目标产 物. 随后，作者以等物质的量的五元环铑中间体与 7-氮 杂苯并降冰片二烯反应, 发现只有在醋酸作为添加剂的 条件下才能顺利地生成目标产物, 这也证明了反应过程 中可能涉及五元环铑中间体并且反应过程中产生的醋 酸是产物生成所必需的. 随后, 该课题组 ${ }^{[27]}$ 通过实验与 理论计算相结合的手段对该反应的机理进行了详细的 探讨, 认为反应可能经过碳氢键活化、烯烃插入、质子 化、亲核进攻生成螺环丙烷化合物, 再经重排得到最终 目标产物. 同时他们使用 $N$-(1-荎氧基)乙酰胺作为反应 的底物, 合成了一类新型的去芳构化的螺环丙烷类分 子. 值得注意的是, $N$-(1-菜氧基)乙酰胺作为一碳单元用 于目标分子的构建.

2014 年, 赵劲、洪梅和陈波等 ${ }^{[28]}$ 报道了铑催化的 $N$-苯氧基酰胺与 $\alpha, \beta$-不饱和醛的碳氢键活化反应, 实现 了苯并七元杂环的构建 (Scheme 21). 该反应在室温条 件下进行, 具有良好的官能团容忍性和底物普适性. 在 标准反应条件下, 当以 $\alpha, \beta$-不饱和酮作为反应底物时,
仅以中等产率得到导向基邻位双烷基化产物 2, 并未得 到环化产物. 有意思的是, 当以 $N$-苯氧基苯甲酰胺作为 反应底物时, 在标准反应条件下与丙烯醛反应, 碳氢键 活化优先发生苯甲酰胺的苯环上，以 $80 \%$ 的产率得到产 物 3. 目标产物在 $\mathrm{Pd} / \mathrm{C}$ 和氢气条件下经后续转化可以得 到色满衍生物，体现了该反应具有一定的合成应用价 值.

除了铑催化剂以外, 钴催化剂也可用于催化 $N$-苯 氧基乙酰胺与烯烃的碳氢键活化反应. 2016 年, Glorius 课题组 ${ }^{[29]}$ 使用 $\left[\mathrm{Cp}^{*} \mathrm{Co}(\mathrm{CO}) \mathrm{I}_{2}\right]$ 作为催化剂, 以 $N$-苯氧基 乙酰胺与丙烯酸酯作为反应底物, 实现了非天然氨基酸 衍生物的合成, 在反应产物中同时构建了一根碳碳键和 碳氮键(Scheme 22). 推测的反应机理包括碳氢键活化、 烯烃插入、还原消除、氧化加成和质子化等过程. 值的 一提的是, 在铑催化体系中, 未达到配位饱和的铑中间 体优先发生 $\beta$-氢消除, 得到导向基邻位烯基化产物, 而 在钴的催化体系中, 未达配位饱和的七元环钴中间体更 倾向于还原消除，从而得到导向基邻位烷基化的产物. 


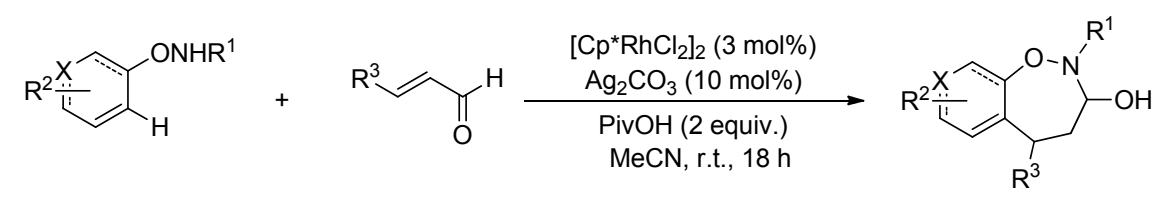<smiles>CN1Oc2ccccc2CCC1O</smiles>

93\%<smiles>O=C(O)N1Oc2ccccc2CCC1O</smiles>

$40 \%$<smiles>COc1ccc2c(c1)ON(C(=O)O)C(O)CC2</smiles>

$40 \%$<smiles>CC(C)N1Oc2cc(F)ccc2CCC1O</smiles>

$92 \%$<smiles>CC(C)N1Oc2ccc(Br)cc2CCC1O</smiles><smiles>CCCCCN1Oc2ccc(C(C)=O)cc2CCC1O</smiles><smiles>CC(C)N1OC2CCCC=C2CCC1O</smiles>

$81 \%$<smiles>CCC1CC(O)N(C(C)C)Oc2ccccc21</smiles>

$96 \%$

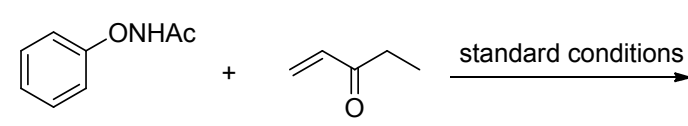<smiles>CCCCOc1c(CCC(=O)CC)cccc1CCC(=O)CC</smiles>

$248 \%$<smiles>C=CC=O</smiles><smiles>O=C1c2ccccc2CCC(O)N1Oc1ccccc1</smiles>

$380 \%$

图式 21 铑催化的 $N$-苯氧基酰胺与 $\alpha, \beta$-不饱和醛的碳氢键活化反应

Scheme 21 Rhodium-catalyzed $\mathrm{C}-\mathrm{H}$ bond activation of $N$-phenoxyamides with $\alpha, \beta$-unsaturated aldehydes
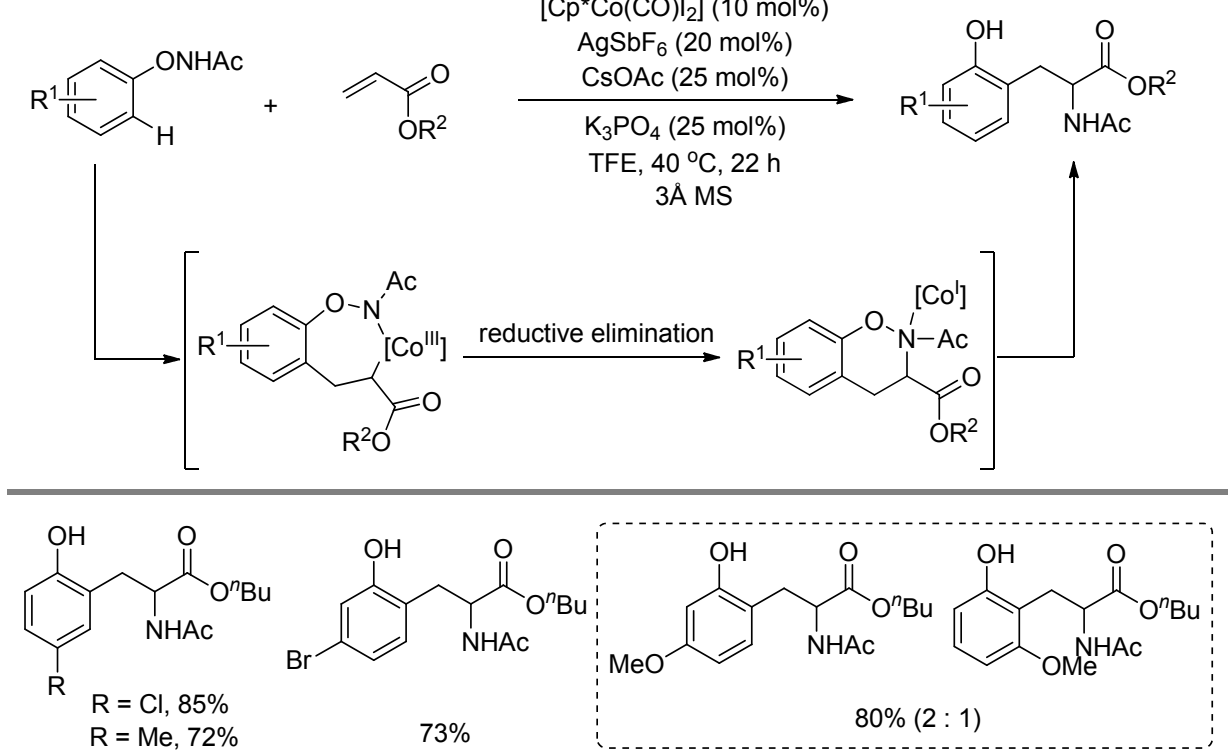

图式 22 钴催化的 $N$-苯氧基乙酰胺与丙烯酸酯的碳氢键活化反应

Scheme 22 Cobalt-catalyzed $\mathrm{C}-\mathrm{H}$ bond activation of $N$-phenoxyacetamides with acrylates

\section{3 重氮化合物作为偶联组分}

2014 年, 王剑波课题组 ${ }^{[30]}$ 利用对甲苯磺酰腙和 $\alpha-$ 酯基重氮化合物作为反应底物，在 $\left[\left(\mathrm{Cp}^{*} \mathrm{RhCl}_{2}\right)_{2}\right]$ 催化作 用下与 $N$-苯氧基乙酰胺发生反应, 通过碳氢键活化得
到了邻烯基取代的苯酚类衍生物(Scheme 23)。该反应 操作简单，具有高度的立体选择性和良好的底物普适 性. 作者推测反应的机理为: $\left[\left(\mathrm{Cp}^{*} \mathrm{RhCl}_{2}\right)_{2}\right]$ 首先与醋酸 盐发生阴离子交换生成催化活性物种 $\left[\mathrm{Cp} * \mathrm{Rh}(\mathrm{OAc})_{2}\right]$, 
随后与 $N$-苯氧基乙酰胺反应得到五元环铑中间体, 反 应体系中的重氮化合物被该中间体分解生成铑卡宾, 芳 基迁移到铑卡宾碳原子上得到六元环铑中间体, 经过 $\beta$ 氢消除和还原消除生成一价铑中间体，导向基中的 $\mathrm{N}$ $\mathrm{O}$ 键对一价铑氧化后经质子化得到目标产物, 同时再生 催化剂(Scheme 24). 在这一系列过程中, 铑卡宾的转移 插入被认为是该反应的关键步骤. 2018 年, 张艳等 ${ }^{[31]}$ 报 道了铑催化的 $N$-苯氧基乙酰胺、酮和水合肼的一锅三组 分反应，快速合成了一系列邻位烯基取代的苯酚类衍生 物. 在该反应中, 酮与水合肼缩合得到腙, 经二氧化锰 氧化生成重氮化合物, 与 $N$ - 苯氧基乙酰胺在 $\left[\left(\mathrm{Cp}^{*} \mathrm{RhCl}_{2}\right)_{2}\right]$ 催化作用下反应得到目标产物, 该反应的 机理与以上报道 ${ }^{[30]}$ 相同.

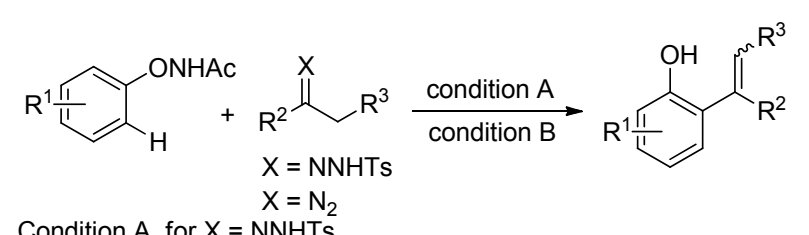

Condition $\mathrm{A}$ for $\mathrm{X}=\mathrm{NNHTS}$

$\left[\mathrm{Cp}^{*} \mathrm{RhCl}_{2}\right]_{2}(2.5 \mathrm{~mol} \%), \mathrm{LiO}^{t} \mathrm{Bu}$ (1.0 equiv),

$\mathrm{NaOAc}$ (1.0 equiv), toluene, $90^{\circ} \mathrm{C}, 16 \mathrm{~h}$.

condition $\mathrm{B}$ for $\mathrm{X}=\mathrm{N}_{2}$

$\left[\mathrm{Cp}^{*} \mathrm{RhCl}_{2}\right]_{2}(2.5 \mathrm{~mol} \%), \mathrm{AgOAc}(20 \mathrm{~mol} \%)$,

DCE, $30{ }^{\circ} \mathrm{C}, 18 \mathrm{~h}$.

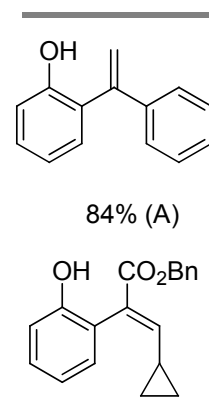

$76 \%(B)$<smiles>C=C(c1cccc(OC)c1)c1ccccc1O</smiles>

$71 \%(\mathrm{~A})$<smiles>CC/C=C(\C(C)=O)c1ccccc1O</smiles>

$94 \%(B)$
$79 \%(A)$<smiles>CC/C=C(\C(C)=O)c1cc(F)ccc1O</smiles>

$70 \%(\mathrm{~B})$
图式 23 铑催化的 $N$-苯氧基乙酰胺与对甲苯磺酰腙或 $\alpha$-酯基 重氮化合物的碳氢键活化反应

Scheme 23 Rhodium-catalyzed $\mathrm{C}-\mathrm{H}$ bond activation of $N$-phenoxyacetamides with $N$-tosylhydrazones or $\alpha$-diazoesters

2015 年, 易伟和 $\mathrm{Xu}$ 等 ${ }^{[32]}$ 发展了铑催化的 $N$-苯氧基 乙酰胺与重氮丙二酸酯的碳氢键活化反应, 合成了一系 列苯酚衍生物(Scheme 25). 在该反应中, 醇不仅作为溶 剂而且还作为反应物参与了反应, 在导向基的邻位构建 了一个四级碳中心. 该反应在室温下进行, 反应条件温 和, 可以兼容各种的电性的 $N$-苯氧基乙酰胺. 反应所得 产物可以发生进一步转化得到产物 4 和 $\mathbf{5}$, 体现了该反 应在合成中的应用价值. 作者通过忥代甲醇标记实验和 动力学同位素标记实验认为碳氢键断裂可能是反应的 决速步骤并且是不可逆的.

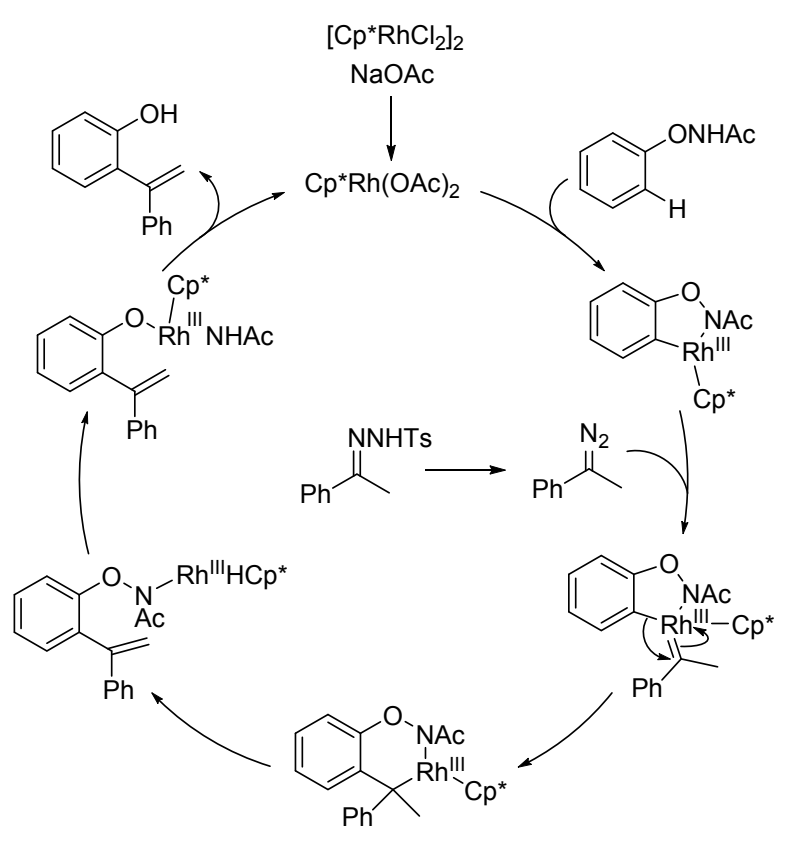

图式 24 可能的反应机理

Scheme 24 Possible reaction mechanism

$$
\text { (2.5 mol\%) }
$$

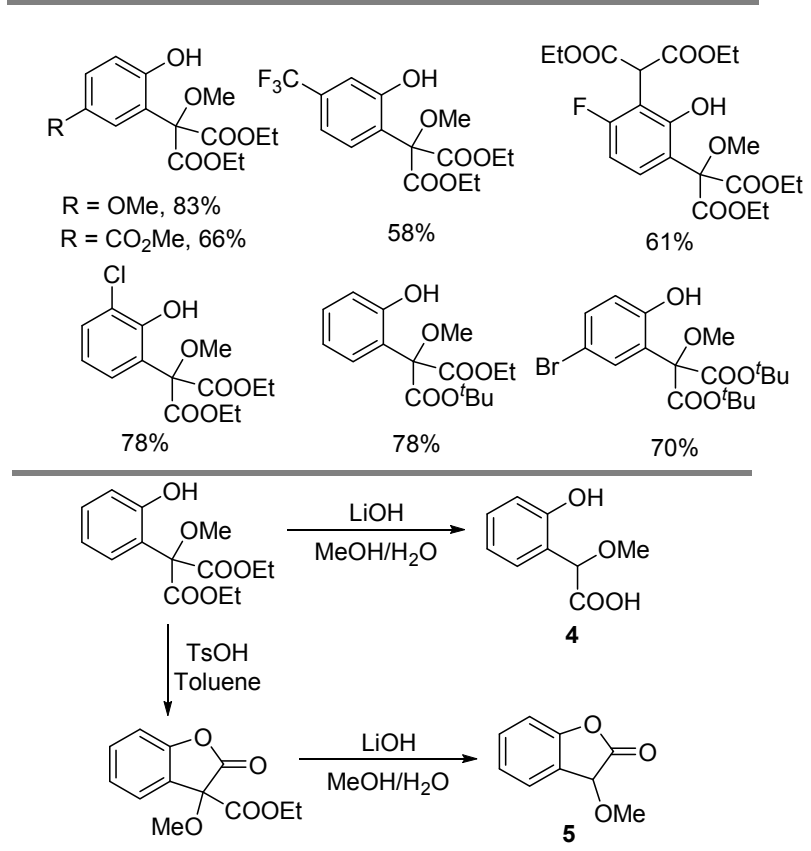

图式 25 铑催化的 $N$-苯氧基乙酰胺与重氮丙二酸酯的碳氢键 活化反应

Scheme 25 Rhodium-catalyzed $\mathrm{C}-\mathrm{H}$ bond activation of $N$-phenoxyacetamides with $\alpha$-diazomalonates 
2017 年, 刘桂霞课题组 ${ }^{[33]}$ 使用 $N$-苯氧基乙酰胺和 环已烯酮重氮化合物作为反应底物, 在 $\left[\left(\mathrm{Cp} * \mathrm{RhCl}_{2}\right)_{2}\right]$ 催 化作用下, 经过碳氢键活化、铑卡宾形成、转移插入、 $\beta$ 氢消除、芳构化、还原消除、氧化加成和质子化等过程， 合成了一系列不对称的邻苯二酚类化合物(Scheme 26). 无论是简单的反应底物还是复杂的反应底物, 如 $L$-酪氨 酸和䧳酮的衍生物都能顺利发生反应，体现了该反应良 好的底物普适性. 当使用含有手性基团的大位阻重氮化 合物时，对映选择性能够保持但反应产率很低. 值得一 提的是，该反应能够进行克级制备，产率几乎不受影响.

2018 年, 周兵和朱维良等 ${ }^{[34]}$ 使用 $\left[\left(\mathrm{Cp}^{*} \mathrm{RhCl}_{2}\right)_{2}\right] /$ $\mathrm{CsOAc}$ 作为催化体系, 以重氮丙二酸酯作为偶联组分, 实现了 $N$-苯氧基酰胺的双碳氢键官能团化, 在目标产 物中同时构建了一根碳碳键和一根碳氮键(Scheme 27). 多巴胺和䧳酮衍生的 $N$-苯氧基乙酰胺与重氮丙二酸酯 在标准反应条件下可以顺利的发生反应, 说明该反应可 用于目标分子的后期修饰，同时也体现了该反应具有良 好的底物普适性. 目标产物经后续转化可以生成苯并噁 噁唑和苯酞衍生物，显示了该反应具有良好的合成应用 价值. 通过机理实验和理论计算研究，作者认为反应机 理中可能涉及五价铑氮宾中间体，经质子化和分子内亲 电加成过程生成目标产物.

\section{4 其它偶联组分}

2014 年, 赵劲和张欣豪等 ${ }^{[35]}$ 报道了钯催化的 $N$-苯 氧基乙酰胺与醛的 $[4+1]$ 环化反应, 通过碳氢键活化, 实现了苯并异噁唑类衍生物的合成(Scheme 28). 不同 电性的芳基醛和 $N$-苯氧基乙酰胺都可以顺利地发生反 应，杂环和烷基取代的醛也可以在标准反应条件下得到 兼容. 值得注意的是, 导向基中的 $\mathrm{N}-\mathrm{O}$ 键在该反应中 保持完整，并且参与了环化反应，在目标产物中同时构 建了一根 $\mathrm{C}-\mathrm{C}$ 键和一根 $\mathrm{C}=\mathrm{N}$ 键. 作者利用该方法合 成了利培酮、帕潘立酮和伊潘立酮的关键中间体，展示 了该反应良好的合成应用价值. 在无叔丁基过氧化氢存 在的条件下，无论在催化量还是等物质的量的三氟乙酸 钯作用下, 均不能得到目标产物, 因此作者认为反应经 过 $\mathrm{Pd}^{\mathrm{II}} / \mathrm{Pd}^{\mathrm{IV}} / \mathrm{Pd}^{\mathrm{II}}$ 催化循环, 理论计算也证实了这一结果.

2015 年, 游劲松和兰静波等 ${ }^{[36]}$ 报道了铑催化的 $N$ 苯氧基乙酰胺与 1,3-二唑类化合物的碳氢键氧化偶联反 应，合成了一系列 2-(2-差基苯基)啞唑类化合物(Scheme 29). 其中啞唑、苯并噁唑、苯并噻唑和苯并咪唑等底物 都可以适用于该反应. 由于目标产物的特殊结构, 它通 过分子内质子转移可以发生酮式和烯醇式的互变异构, 因此，目标产物可能作为潜在的单分子白色有机发光材 料. 作者利用该方法合成了一些结构复杂的目标分子,
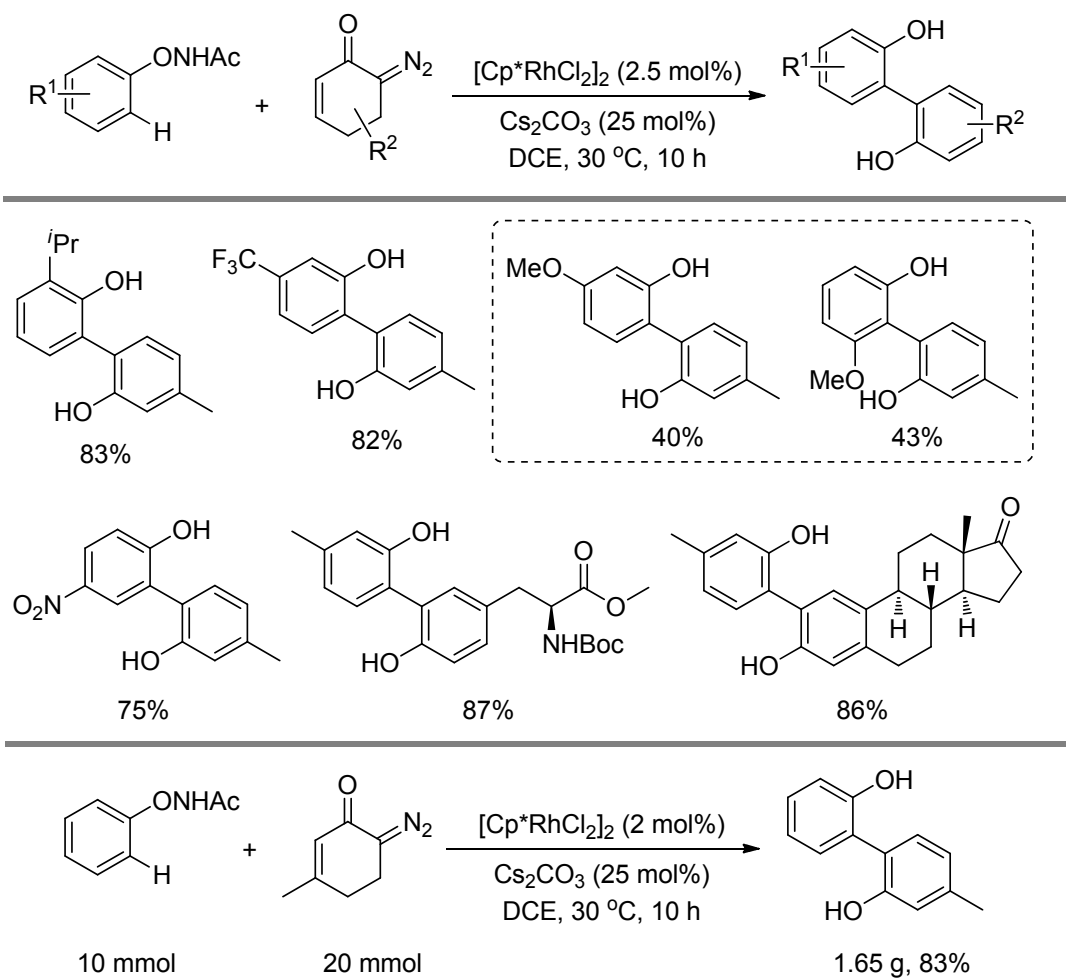

$1.65 \mathrm{~g}, 83 \%$

图式 26 铑催化的 $N$-苯氧基乙酰胺与环己烯酮重氮化合物的碳氢键活化反应

Scheme 26 Rhodium-catalyzed $\mathrm{C}-\mathrm{H}$ bond activation of $N$-phenoxyacetamides with 6-diazo-2-cyclohexenones 


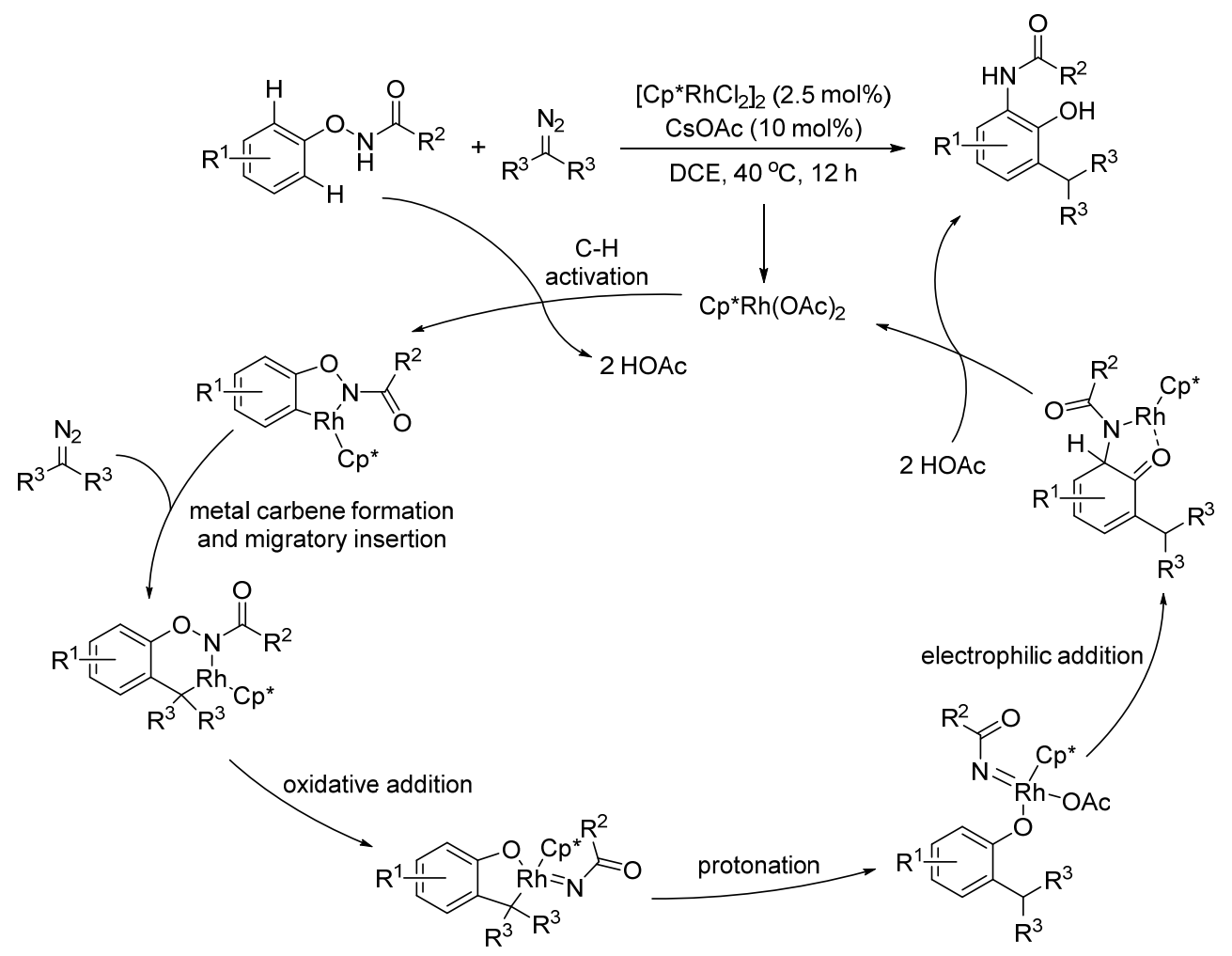

图式 27 铑催化的 $N$-苯氧基酰胺与重氮丙二酸酯的双碳氢键活化反应

Scheme 27 Rhodium-catalyzed double $\mathrm{C}-\mathrm{H}$ bond activation of $N$-phenoxyamides with $\alpha$-diazomalonates

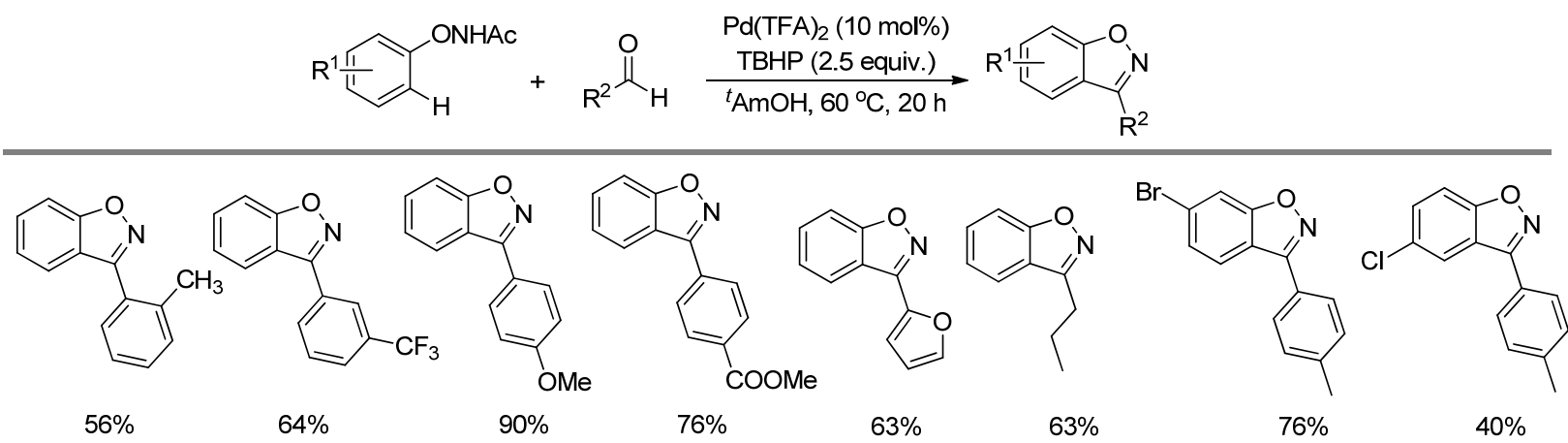

图式 28 钯催化的 $N$-苯氧基乙酰胺与醛的 $[4+1$ ]环化反应

Scheme 28 Palladium-catalyzed [4+1] annulation of $N$-phenoxyacetamides with aldehydes

当 $N$-苯氧基乙酰胺与噁唑中均含有三苯胺基团时, 反 应生成的目标产物 6 和 7 表现出优秀的白色发光性能、 高的量子产率和良好的热稳定性. 随后, 作者利用该方 法合成了深蓝色有机发光材料, 并详细地研究了它的发 光性能 ${ }^{[37]}$. 2017 年, 赵劲课题组 ${ }^{[38]}$ 报道了类似的反应 (Scheme 30). 不同的是, 他们不仅实现了 $N$-苯氧基乙酰 胺导向基邻位的单芳基化, 还可以实现导向基邻位的双 芳基化. 更有意思的是, 他们还可以通过加入氟化银作 为氧化剂, 避免了导向基中 $\mathrm{N}-\mathrm{O}$ 键的断裂, 为产物的 后续转化提供了条件, 可用于合成含有不同芳基的目标 产物.

Glorius 课题组 ${ }^{[39]}$ 最近利用桥环烯烃作为共催化剂,
实现了铑催化 $N$-苯氧基乙酰胺的胺化反应(Scheme 31). 在该反应中，酰胺导向基不仅作为配位基团而且还作为 碳氢键的胺化试剂. 无论是简单的反应底物还是复杂的 天然产物(例如雌酮、酪氨酸)和药物分子(例如叔辛酚 氯)的衍生物均可以顺利的发生反应，以中等到较好的 产率得到目标产物. 作者通过底物的交叉反应实验证明 该反应是分子内进行的. $N$-苯氧基乙酰胺与 $[(\mathrm{Cp} * \mathrm{Rh}-$ $\left.\mathrm{Cl}_{2}\right)_{2}$ ] 经碳氢键活化得到五元环铑中间体 $\mathbf{8}$, 在桥环烯烃 作用下生成一种新的五元环铑中间体 9. 随后，作者以 五元环铑中间体 9 作为催化剂，在 $20 \mathrm{~mol} \%$ 的醋酸作为 添加剂的条件下，该反应能够高效的进行，而在无添加 剂的条件下，仅能以 $9 \%$ 的核磁产率得到目标产物，这 


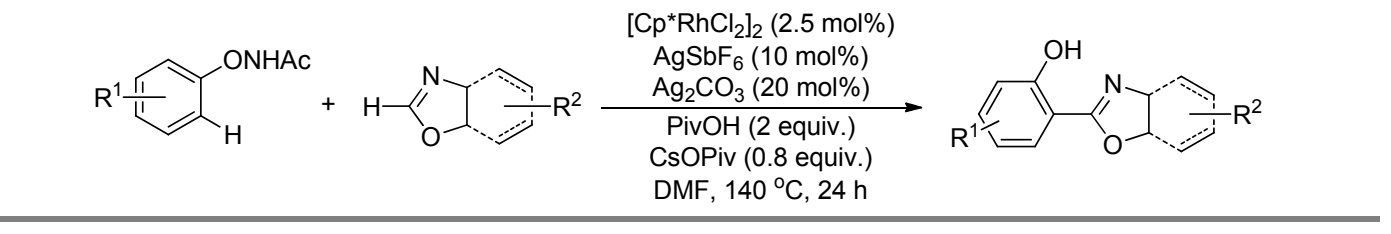<smiles>Oc1ccccc1-c1nc2cc(F)ccc2o1</smiles>

$\mathrm{R}=\mathrm{Me}, 73 \%$

$\mathrm{R}=\mathrm{Cl}, 82 \%$<smiles>COc1ccccc1-c1cnc(-c2ccccc2O)o1</smiles>

$82 \%$

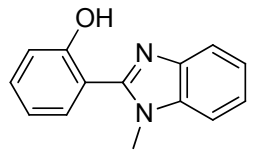

$72 \%$

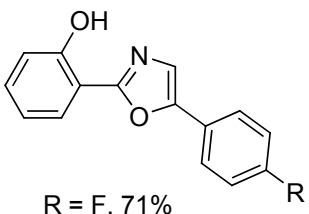

$\mathrm{R}=\mathrm{F}, 71 \%$
$\mathrm{R}=\mathrm{CN}, 88 \%$<smiles>Cc1cccc(-c2nc3ccccc3s2)c1O</smiles>

$66 \%$

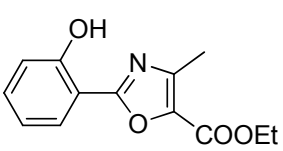

$59 \%$<smiles>COc1ccc(-c2nc3ccccc3o2)c(O)c1</smiles>

$71 \%$<smiles>Cc1cc(F)cc(-c2nc3ccccc3o2)c1O</smiles>

$82 \%$

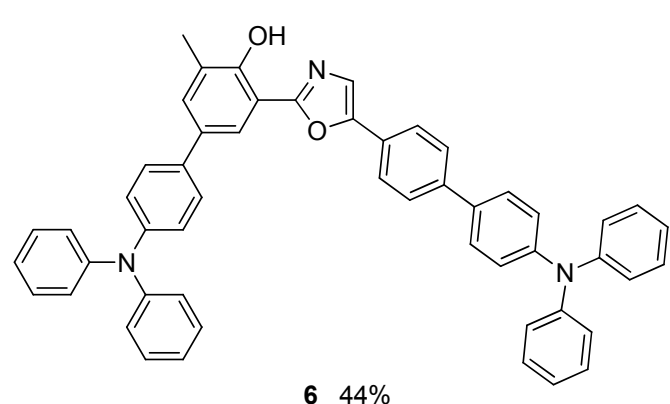

$644 \%$

$\lambda_{\mathrm{abs}}=310,378 \mathrm{~nm}, \lambda_{\mathrm{em}}=423,546 \mathrm{~nm}$,

$\Phi_{\mathrm{f}}=57 \%$ (in solution)

$\lambda_{\mathrm{abs}}=259,310,373 \mathrm{~nm}, \lambda_{\mathrm{em}}=445,542 \mathrm{~nm}$, $\Phi_{\mathrm{f}}=62 \%$ (in PS)

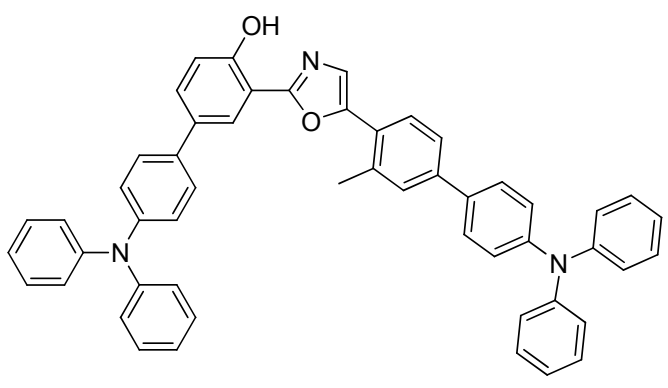

$7 \quad 51 \%$

$\lambda_{\mathrm{abs}}=309,370 \mathrm{~nm}, \lambda_{\mathrm{em}}=449,564 \mathrm{~nm}$,

$\Phi_{\mathrm{f}}=77 \%$ (in solution)

$\lambda_{\mathrm{abs}}=259,306,369 \mathrm{~nm}, \lambda_{\mathrm{em}}=444,540 \mathrm{~nm}$,

$\Phi_{\mathrm{f}}=56 \%$ (in PS)

图式 29 铑催化的 $N$-苯氧基乙酰胺与 1,3-二唑类化合物的碳氢键氧化偶联反应

Scheme 29 Rhodium-catalyzed oxidative $\mathrm{C}-\mathrm{H}$ bond activation of $N$-phenoxyacetamides with 1,3-diazole
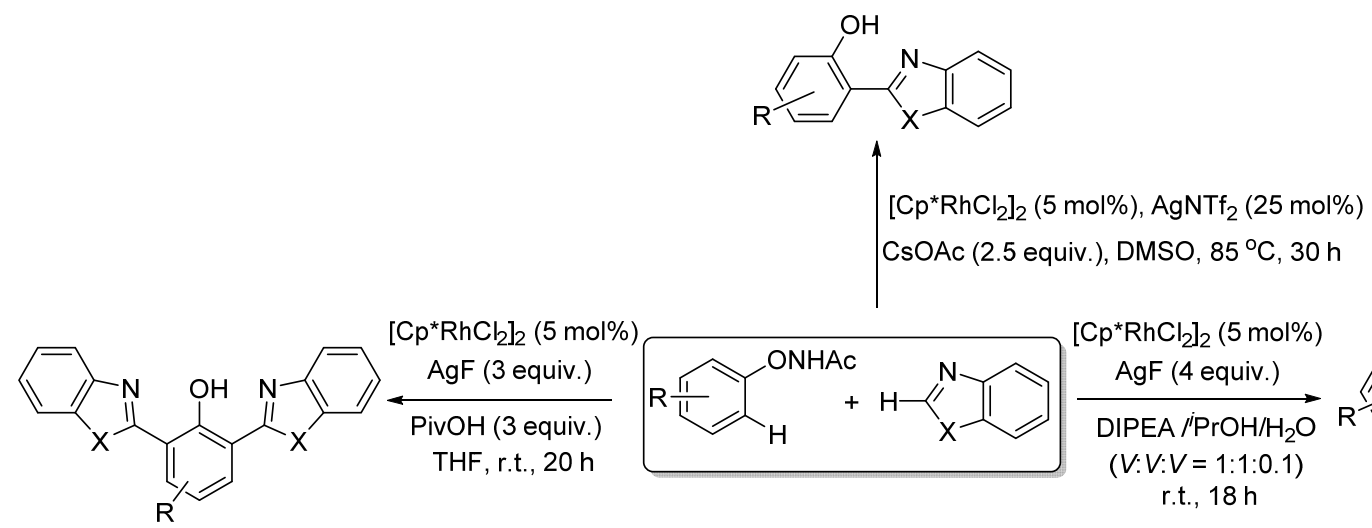

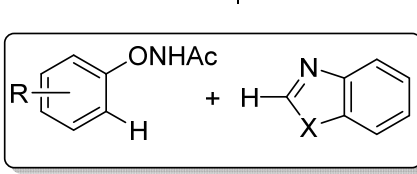

$\mathrm{H}$

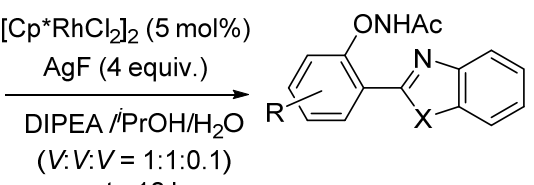

r.t., $18 \mathrm{~h}$

图式 30 铑催化的 $N$-苯氧基乙酰胺与苯并噻唑或苯并啞唑的碳氢键氧化偶联反应

Scheme 30 Rhodium-catalyzed oxidative $\mathrm{C}-\mathrm{H}$ bond activation of $\mathrm{N}$-phenoxyacetamides with benzothiazoles or benzoxazoles

说明反应过程中生成的醋酸对该反应的顺利进行起着 重要的作用. 在机理实验和理论计算的基础上, 作者认 为桥环烯烃促进了 $\mathrm{N}-\mathrm{O}$ 键对七元环铑中间体的氧化加 成和铑氮宾中氮原子对邻位碳原子的亲电加成.
赵劲等 ${ }^{[40]}$ 报道了以 $N$-苯氧基乙酰胺作为反应底物, 在 $\left[\left(\mathrm{Cp}^{*} \mathrm{IrCl}_{2}\right)_{2}\right]$ 的催化作用下, 实现了邻苯二酚的合成 (Scheme 32). 该反应在室温条件下进行，反应条件温 和, 官能团的兼容性好. 一些结构复杂的 $N$-苯氧基乙酰 

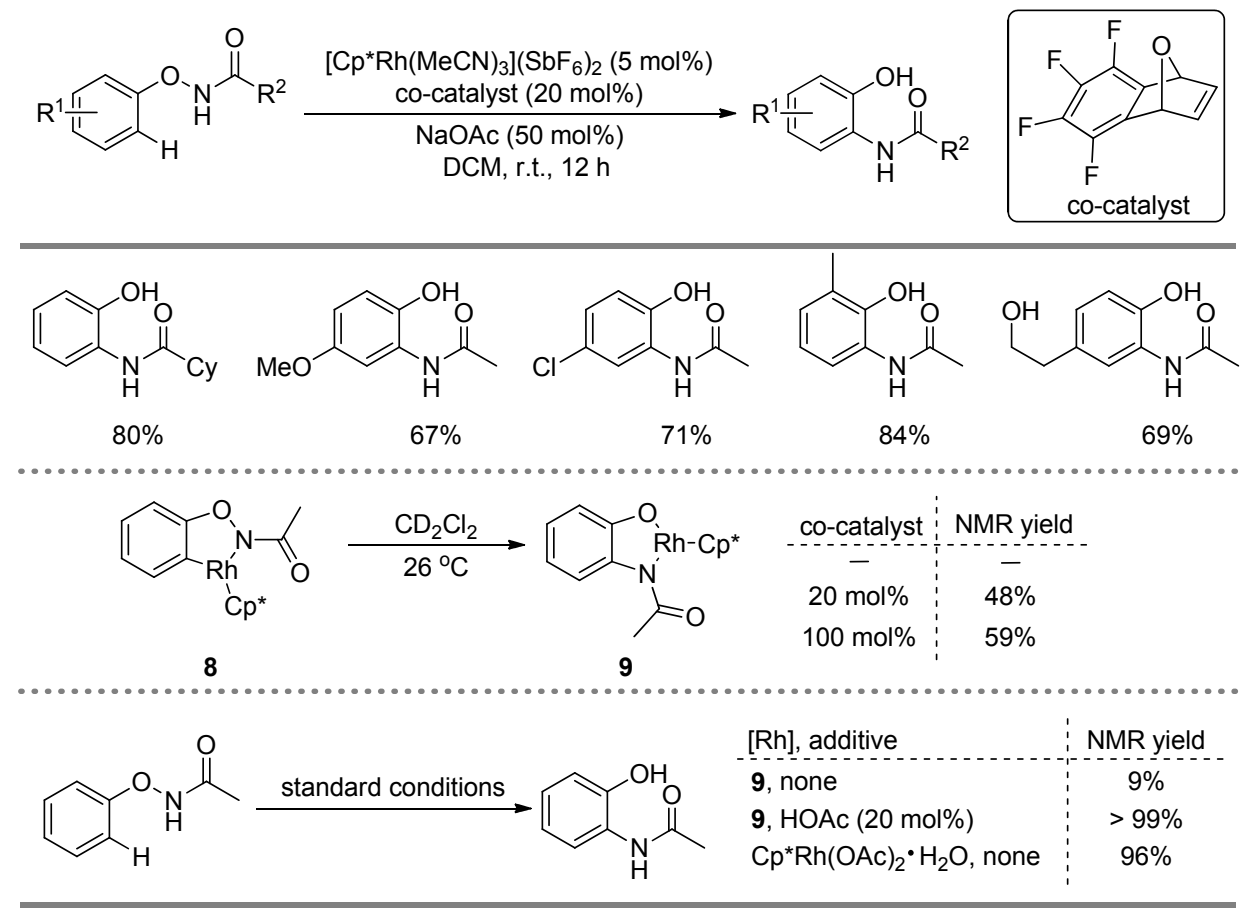

图式 31 铑/烯烃共催化的 $N$-苯氧基乙酰胺分子内碳氢键胺化反应

Scheme 31 Rhodium/olefin cocatalyzed intramolecular C-H bond amidation of $N$-phenoxyacetamides
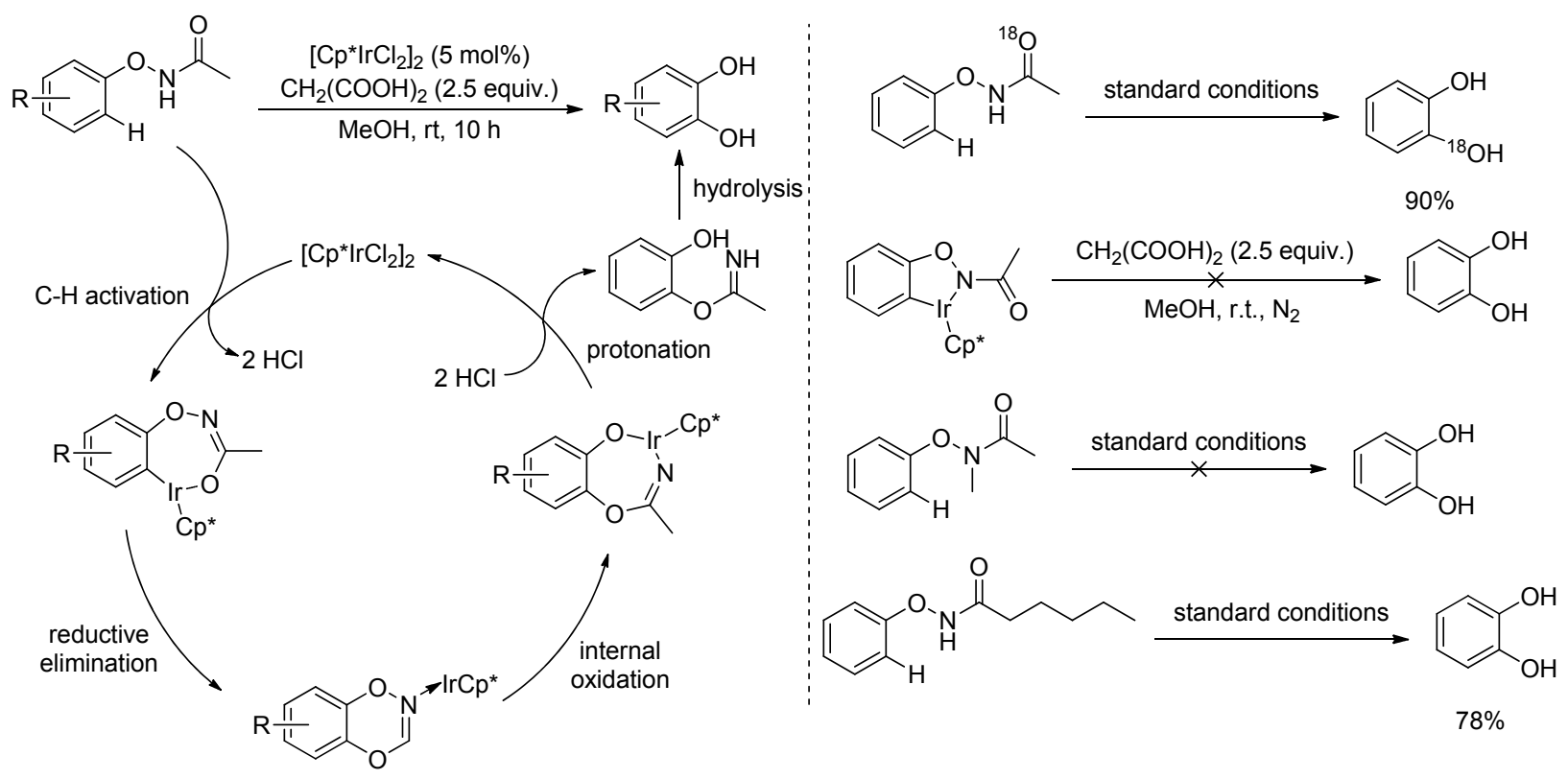

图式 32 铑催化的邻苯二酚类化合物的合成

Scheme 32 Rhodium-catalyzed synthesis of catechol

胺同样适用于该反应，例如作者利用该方法合成了天然 产物左旋多巴和雌二醇. 作者用 ${ }^{18} \mathrm{O}$ 同位素标记实验证 明了目标产物中的羟基来自于导向基，同时也说明了该 反应是经分子内过程进行的. 为了探索反应的中间体, 作者通过 $N$-苯氧基乙酰胺与 $\left[\left(\mathrm{Cp}^{*} \mathrm{IrCl}_{2}\right)_{2}\right]$ 反应得到了五 元环铱中间体，但该中间体在标准反应条件下不能转化 得到目标产物，说明五元环铱可能不是该反应的中间 体. 随后, 作者发现 $N$-甲基取代的苯氧基乙酰胺在标准
反应条件下不能生成目标产物，而 $N$-苯氧基己酰胺可 以顺利的发生反应得到相同的目标产物，证实了导向基 中的 $\mathrm{N}-\mathrm{H}$ 键在反应过程中发挥着重要的作用, 而酰胺 中烷基取代基的影响则可以忽略. 最终, 作者认为 $N$-苯 氧基乙酰胺在酸性条件下与 $\left[\left(\mathrm{Cp}^{*} \mathrm{IrCl}_{2}\right)_{2}\right]$ 形成七元环铱 中间体，经还原消除后形成碳氧键得到一价铱中间体， 导向基中的 $\mathrm{N}-\mathrm{O}$ 键对一价铱氧化加成后生成三价铱中 间体，质子化得到亚胺产物同时再生三价铱催化剂，最 
后, 亚胺产物水解后得到目标产物. 值得注意的是, 酸 在催化体系中发挥着多重作用，它既可以阻止五元环铱 中间体的生成又可以使七元环铱中间体质子化再生催 化剂和消耗反应体系中生成的胺.

2018 年, 该课题组 ${ }^{[41]}$ 发展了铑催化的 $N$-苯氧基乙 酰胺与炔基高价碘试剂的交叉偶联反应，在室温条件下 实现了芳环的炔基化(Scheme 33). 在以上诸多反应中, 导向基中 $\mathrm{N}-\mathrm{O}$ 键作为内氧化剂, 反应后发生 $\mathrm{N}-\mathrm{O}$ 键 断裂生成相应产物, 而在该反应中, 高价碘试剂不仅作 为偶联组分而且充当氧化剂, 使得导向基保持完整. 虽 然 $N$-苯氧基乙酰胺和 $N$-苯氧基苯甲酰胺均可以顺利的 发生反应, 但是 $N$-苯氧基特戊酰胺由于空间位阻的原 因，几乎不能得到目标产物.<smiles>[R]C#CI1C(=O)OC(=O)c2ccc([R])cc21</smiles>

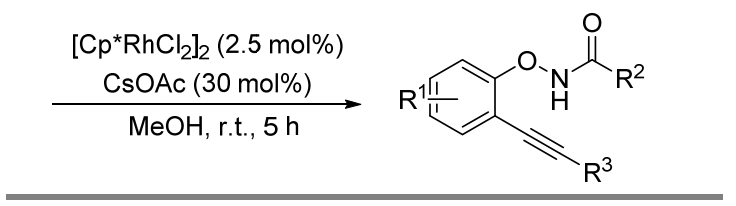<smiles>CC(=O)NOOc1cc(C)ccc1C#C[In]C(F)(F)[In]C#Cc1ccc(Br)cc1ONC(C)=O</smiles><smiles>CC(=O)NOc1ccc(C(=O)O[Na])cc1C#CC(F)(F)F</smiles><smiles>CC(=O)NOc1cc(C)c(C)cc1C#CC(=O)ONC(=O)c1ccccc1</smiles>

图式 33 铑催化的 $N$-苯氧基乙酰胺与炔基高价碘试剂的交叉 偶联反应

Scheme 33 Rhodium-catalyzed cross-coupling reactions of $\mathrm{N}$-phenoxyacetamides with hypervalent iodine-alkyne reagents

\section{5 总结与展望}

根据偶联组分的不同综述了 $N$-苯氧基乙酰胺在有 机合成领域特别是碳氢键活化反应中的应用, 与传统的 碳氢键活化反应相比, $N$-苯氧基乙酰胺中 $\mathrm{N}-\mathrm{O}$ 键作为 内氧化剂可以实现催化剂的再生, 从而避免了等物质的 量外加氧化剂的使用, 使反应可以在氧化还原中性的条
件下进行，因此，这类反应普遍具有良好的官能团兼容 性和底物普适性. 对于该类反应的机理, 最初的研究认 为反应经过 $\mathrm{Rh}^{\mathrm{III}} / \mathrm{Rh}^{\mathrm{I}} / \mathrm{Rh}^{\mathrm{III}}$ 的催化循环, 后续理论计算证 明 $\mathrm{Rh}^{\mathrm{III}} / \mathrm{Rh}^{\mathrm{V}} / \mathrm{Rh}^{\mathrm{III}}$ 的催化循环是一种更有利的形式, 反应 过程中可能涉及五价铑氮宾中间体，这为后续反应的设 计提供了重要的理论支持.

$N$-苯氧基乙酰胺在有机合成中的应用已取得了不 少重要的研究进展, 铑、钉、铱、钴和钯催化剂的使用 实现了结构多样化目标产物的合成, 值得注意的是, 在 这几类金属催化剂中，铑研究的最多，使用的最为广泛， 而其它几种金属催化剂研究的相对较少, 这无疑限制了 $N$-苯氧基乙酰胺在有机合成中的应用范围. 其次，与 $N$ 苯氧基乙酰胺发生偶联反应的组分主要集中在炔烃、烯 烃、重氮和一些杂环化合物, 其它的偶联组分有待于进 一步发掘. 总体来说, 随着氧化还原中性碳氢键活化反 应的发展, $N$-苯氧基乙酰胺在有机合成领域特别是碳氢 键活化反应中将得到更加广泛的应用.

\section{References}

[1] For selected reviews: (a) Colby, D. A.; Bergman, R. G.; Ellman, J. A. Chem. Rev. 2010, 110, 624 .

(b) Colby, D. A.; Tsai, A. S.; Bergman, R. G.; Ellman, J. A. Acc. Chem. Res. 2012, 45, 814.

(c) Song, G.; Wang, F.; Li, X. Chem. Soc. Rev. 2012, 41, 3651 .

(d) Gensch, T.; Hopkinson, M. N.; Glorius, F.; Wencel-Delord, J. Chem. Soc. Rev. 2016, 45, 2900.

(e) Gulías, M.; Mascareñas, J. L. Angew. Chem. Int. Ed. 2016, 55, 11000 .

(f) Hummel, J. R.; Boerth, J. A.; Ellman, J. A. Chem. Rev. 2017, $117,9163$.

[2] For reviews, see: (a) Huang, H.; Ji, X.; Wu, W.; Jiang, H. Chem. Soc. Rev. 2015, 44, 1155.

(b) Hu, Z.; Tong, X.; Liu, G. Chin. J. Org. Chem. 2015, 35, 539 (in Chinese).

(胡志勇, 童晓峰, 刘桂霞, 有机化学, 2015, 35, 539.)

(c) Mo, J.; Wang, L.; Liu, Y.; Cui, X. Synthesis 2015, 47, 439.

(d) Sun, H.; Huang, Y. Synlett 2015, 26, 2751.

[3] Liu, G.; Shen, Y.; Zhou, Z.; Lu, X. Angew. Chem. Int. Ed. 2013, 52, 6033.

[4] Yang, Y.-F.; Houk, K. N.; Wu, Y.-D. J. Am. Chem. Soc. 2016, 138, 6861.

[5] Chen, Y.; Wang, D.; Duan, P.; Ben, R.; Dai, L.; Shao, X.; Hong, M.; Zhao, J.; Huang, Y. Nat. Commun. 2014, 5, 4610.

[6] Zhou, Z.; Liu, G.; Shen, Y.; Lu, X. Org. Chem. Front. 2014, 1, 1161.

[7] Zhou, Z.; Liu, G.; Chen, Y.; Lu, X. Org. Lett. 2015, 17, 5874.

[8] Xie, Y. Chem. Commun. 2016, 52, 12372.

[9] Yi, W.; Chen, W.; Liu, F.-X.; Zhong, Y.; Wu, D.; Zhou, Z.; Gao, H. ACS Catal. 2018, 8, 9508.

[10] Chen, W.; Liu, F.-X.; Gong, W.; Zhou, Z.; Gao, H.; Shi, J.; Wu, B.; Yi, W. Adv. Synth. Catal. 2018, 360, 2470.

[11] Zhou, W.; Mei, Y.-L.; Li, B.; Guan, Z.-Y.; Deng, Q.-H. Org. Lett. 2018, 20, 5808.

[12] Wang, H.; Wang, B.; Li, B. J. Org. Chem. 2017, 82, 9560.

[13] Li, Y.; Shi, D.; Tang, Y.; He, X.; Xu, S. J. Org. Chem. 2018, 83, 9464.

[14] Li, Y.; Shi, D.; He, X.; Wang, Y.; Tang, Y.; Zhang, J.; Xu, S. J. Org. Chem. 2019, 84, 1588.

[15] Zhou, J.; Shi, J.; Qi, Z.; Li, X.; Xu, H. E.; Yi, W. ACS Catal. 2015, 
$5,6999$.

[16] Shen, Y.; Liu, G.; Zhou, Z.; Lu, X. Org. Lett. 2013, 15, 3366.

[17] Hu, Z.; Tong, X.; Liu, G. Org. Lett. 2016, 18, 1702.

[18] Li, Y.; Tang, Y.; He, X.; Shi, D.; Wu, J.; Xu, S. Chem. Eur. J. 2017, 23, 7453.

[19] Prakash, S.; Muralirajan, K.; Cheng, C.-H. Chem. Commun. 2015, 51, 13362.

[20] Wang, Y.; Chen, Y.; Yang, Y.; Zhou, B. Org. Chem. Front. 2018, 5, 1844

[21] Zhou, Z.; Bian, M.; Zhao, L.; Gao, H.; Huang, J.; Liu, X.; Yu, X.; Li. X.; Yi, W. Org. Lett. 2018, 20, 3892.

[22] Zhang, H.; Wang, K.; Wang, B.; Yi, H.; Hu, F.; Li, C.; Zhang, Y.; Wang, J. Angew. Chem., Int. Ed. 2014, 53, 13234.

[23] Guo, W.; Xia, Y. J. Org. Chem. 2015, 80, 8113

[24] Li, J.; Qiu, Z. J. Org. Chem. 2015, 80, 10686.

[25] Wang, X.; Lerchen, A.; Daniliuc, C. G.; Glorius, F. Angew. Chem., Int. Ed. 2018, 57, 1712

[26] Wang, X.; Lerchen, A.; Gensch, T.; Knecht, T.; Daniliuc, C. G.; Glorius, F. Angew. Chem. Int. Ed. 2017, 56, 1381.

[27] Wang, X.; Li, Y.; Knecht, T.; Daniliuc, C. G.; Houk, K. N.; Glorius, F. Angew. Chem. Int. Ed. 2018, 57, 5520.

[28] Duan, P.; Lan, X.; Chen, Y.; Qian, S.-S.; Li, J. J.; Lu, L.; Lu, Y.; Chen, B.; Hong, M.; Zhao, J. Chem. Commun. 2014, 50, 12135.

[29] Lerchen, A.; Knecht, T.; Daniliuc, C. G.; Glorius, F. Angew. Chem.,
Int. Ed. 2016, 55, 15166.

[30] Hu, F.; Xia, Y.; Ye, F.; Liu, Z.; Ma, C.; Zhang, Y.; Wang, J. Angew. Chem., Int. Ed. 2014, 53, 1364

[31] Zhang, Y.; He, Y.; Li, L.; Ji, M.; Li, X.-Z.; Zhu, G. J. Org. Chem. 2018, 83, 2898.

[32] Zhou, J.; Shi, J.; Liu, X.; Jia, J.; Song, H.; Xu, H. E.; Yi, W. Chem. Commun. 2015, 51, 5868.

[33] Hu, Z.; Liu, G. Adv. Synth. Catal. 2017, 359, 1643.

[34] Wu, Y.; Chen, Z.; Yang, Y.; Zhu, W.; Zhou, B. J. Am. Chem. Soc. 2018, 140, 42.

[35] Duan, P.; Yang, Y.; Ben, R.; Yan, Y.; Dai, L.; Hong, M.; Wu, Y.-D.; Wang, D.; Zhang, X.; Zhao, J. Chem. Sci. 2014, 5, 1574.

[36] Li, B.; Lan, J.; Wu, D.; You, J. Angew. Chem., Int. Ed. 2015, 54 , 14008 .

[37] Li, B.; Tang, G.; Zhou, L.; Wu, D.; Lan, J.; Zhou, L.; Lu, Z.; You, J. Adv. Funct. Mater. 2017, 27, 1605245.

[38] Wu, Q.; Chen, Y.; Yan, D.; Zhang, M.; Lu, Y.; Sun, W.-Y.; Zhao, J. Chem. Sci. 2017, 8, 169.

[39] Wang, X.; Gensch, T.; Lerchen, A.; Daniliuc, C. G.; Glorius, F. J. Am. Chem. Soc. 2017, 139, 6506.

[40] Wu, Q.; Yan, D.; Chen, Y.; Wang, T.; Xiong, F.; Wei, W.; Lu, Y.; Sun, W.-Y.; Li, J. J.; Zhao, J. Nat. Commun. 2017, 8, 14227.

[41] Hu, S.; Lu, L.; Zhu, T.; Wu, Q.; Chen, Y.; Li, J. J.; Zhao, J. Org. Biomol. Chem. 2018, 16, 43 . 